2017-07-01

\title{
Continuous Permeability Measurement During Unidirectional Vacuum Infusion Processing
}

David Wayne Hoagland

Brigham Young University

Follow this and additional works at: https://scholarsarchive.byu.edu/etd

Part of the Industrial Technology Commons

\section{BYU ScholarsArchive Citation}

Hoagland, David Wayne, "Continuous Permeability Measurement During Unidirectional Vacuum Infusion Processing" (2017). All Theses and Dissertations. 6457.

https://scholarsarchive.byu.edu/etd/6457

This Thesis is brought to you for free and open access by BYU ScholarsArchive. It has been accepted for inclusion in All Theses and Dissertations by an authorized administrator of BYU ScholarsArchive. For more information, please contact scholarsarchive@byu.edu, ellen_amatangelo@byu.edu. 


\title{
Continuous Permeability Measurement
}

\author{
During Unidirectional Vacuum
}

\author{
Infusion Processing
}

David Wayne Hoagland

\begin{abstract}
A thesis submitted to the faculty of
Brigham Young University

in partial fulfillment of the requirements for the degree of

Master of Science
\end{abstract}

\author{
Andrew R. George, Chair \\ Michael P. Miles \\ David T. Fullwood
}

\author{
School of Technology \\ Brigham Young University
}

Copyright (C) 2017 David Wayne Hoagland

All Rights Reserved 


\author{
ABSTRACT \\ Continuous Permeability Measurement \\ During Unidirectional Vacuum \\ Infusion Processing \\ David Wayne Hoagland \\ School of Technology, BYU \\ Master of Science
}

Composite materials have traditionally been used in high-end aerospace parts and lowend consumer parts. The reason for this separation in markets is the wide gap in technology between pre-preg materials processed in an autoclave and chop strand fiberglass blown into an open mold. Liquid composite molding has emerged as a bridge between inexpensive tooling and large, technical parts. Processes such as vacuum infusion have made it possible to utilize complex layups of reinforcement materials in an open mold style set-up, creating optimal conditions for composites to penetrate many new markets with rapid innovation.

Flow simulation for liquid composite molding is often performed to assist in process optimization, and requires the permeability of the reinforcement to be characterized. For infusion under a flexible membrane, such as vacuum infusion, or for simulation of a part with nonuniform thickness, one must test the permeability at various levels of compaction. This process is time consuming and often relies on interpolation or extrapolation around a few experimental permeability measurements. To accelerate the process of permeability characterization, a small number of methodologies have been previously presented in the literature, in which the permeability may be tested at multiple fiber volume contents in a single test. Some of the methods even measure the permeability over a continuous range of thicknesses, thus requiring no later interpolation of permeability values.

A novel method is presented here for the rapid measurement of permeability over a continuous range of fiber volume content, in a single unidirectional vacuum infusion flow experiment. The thickness gradient across the vacuum bag, as well as the fluid pressure at several locations in the mold, were concurrently measured to calculate the fabric compressibility. An analytical flow model, which accounts for the compressibility, is then used by iterating the fitting constant in a permeability model until the predicted flow front progression matches empirical measurement. The method is demonstrated here for two reinforcement materials: 1) a fiberglass unbalanced weave and 2) a carbon bi-ax non-crimped fabric. The standard deviation of calculated permeabilities across the multiple infusion experiments for each material and flow orientation ranged from $12.8 \%$ to $29.7 \%$. Validation of these results was performed by comparing the resulting permeability with multiple non-continuous permeability measurement methods.

Keywords: permeability, liquid composite molding, vacuum infusion (VI), fiber volume, compressibility, flow simulation, resin infusion, out-of-autoclave 


\section{ACKNOWLEDGEMENTS}

I would like to thank the faculty and staff of Brigham Young University, the Ira A. Fulton College of Engineering and Technology, and the School of Technology for all they have done to provide a first class educational experience that has enriched my life. I want to thank Dr. Andy George for his contagious excitement about vacuum infusion and the countless hours that he has put in with me testing, analyzing, and explaining this wonderful topic. Additional thanks go to my committee members, Dr. David Fullwood and Dr. Michael Miles, for the time they dedicated to improving this thesis. Special thanks go to Ruth Ann Lowe, for her dedication to the graduate students in this program.

I would like to especially thank my wife, Dani, who has been my support through this endeavor to return to school and further my education. I'm thankful for the extra time she has spent to raise our wonderful boys, Chase, Tanner, Barrett, and Steele, while I have been attending classes, working, studying, and researching. I am additionally grateful for my parents, Dennis and Mary, who have been a constant inspiration and support.

I'm thankful for the support and flexibility shown by RockWell Window Wells to help me through the final steps of this thesis and for the opportunity to do countless infusions, which led to a better understanding of my research. Thank you to Composites One, for donating the carbon fiber material for testing. Finally, I would like to acknowledge and thank my fellow classmates, Mark Brandley, Paul Hannibal, and Mike Morgan. They were excellent colleagues and their research paved the way for this study. 


\section{TABLE OF CONTENTS}

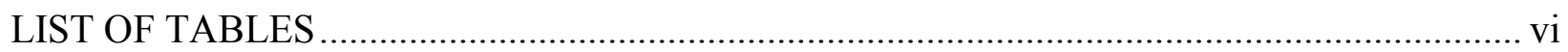

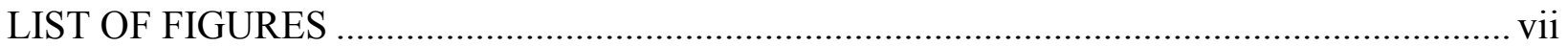

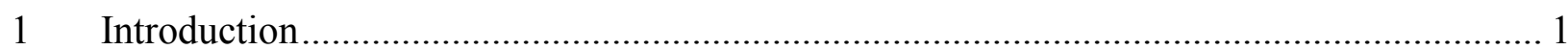

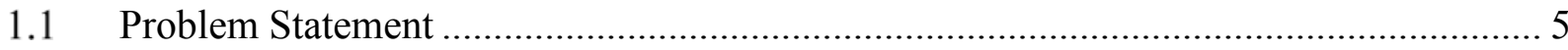

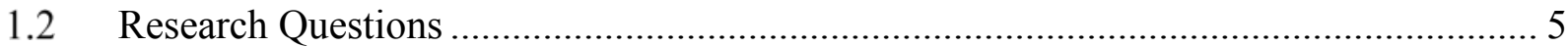

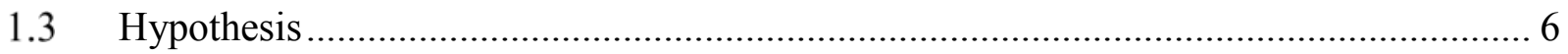

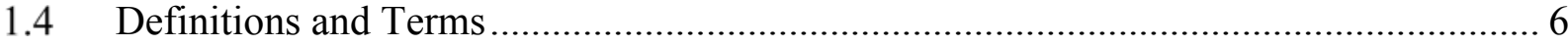

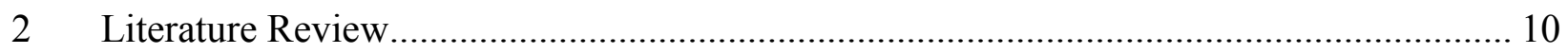

2.1 Liquid Composite Molding .................................................................................. 10

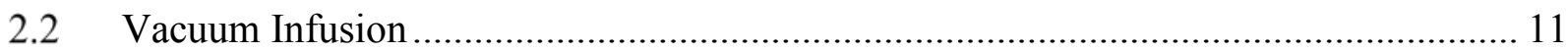

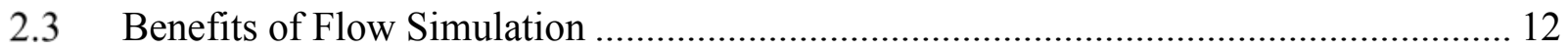

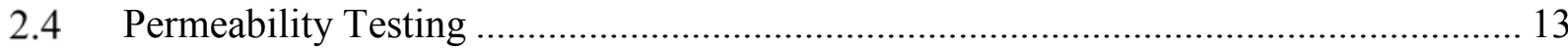

2.5 1-Dimensional In-Plane Testing Methods............................................................. 15

2.6 2-Dimensional In-Plane Testing Methods................................................................. 17

2.7 3-Dimensional Testing Method............................................................................... 19

2.8 Continuous Permeability Measurement Methods ......................................................... 19

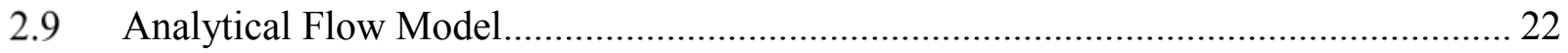

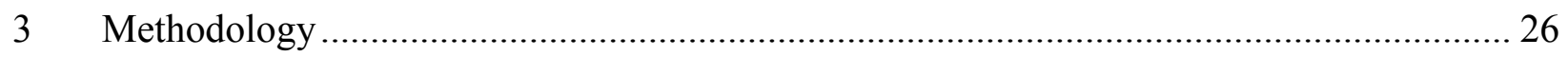

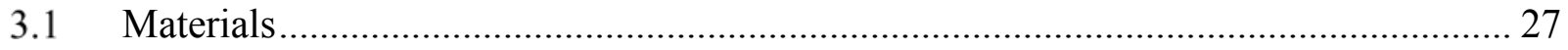

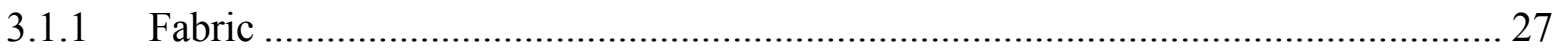

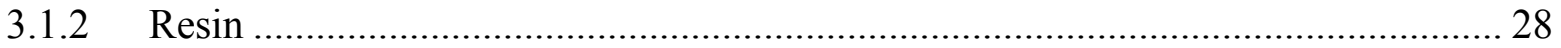

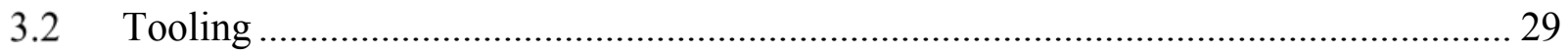




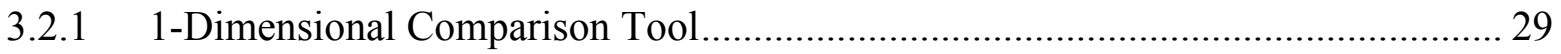

3.2.2 3-Dimensional Comparison Tool.................................................................. 32

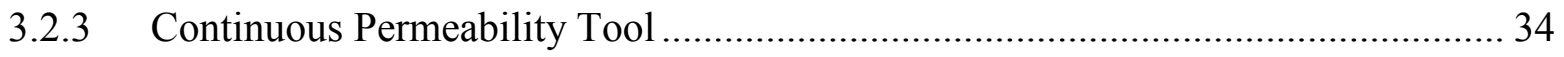

Fiber Orientation and Sample Layup ............................................................ 35

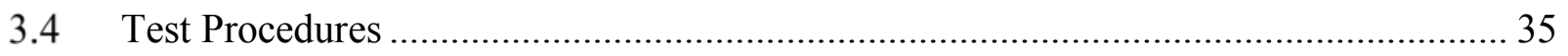

3.5 Compressibility Measurement and Model ....................................................... 36

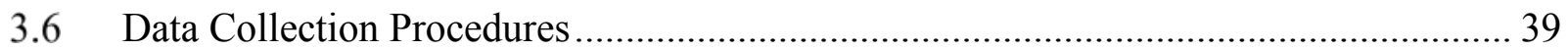

3.6.1 DAQ and DIC Calibration: ....................................................................... 40

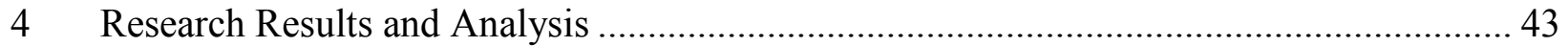

4.1 Choice of Permeability Model ............................................................................ 44

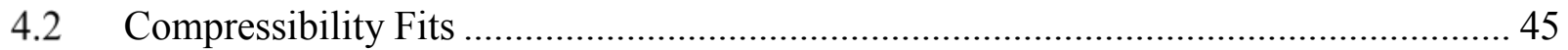

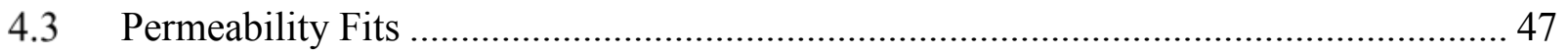

4.4 Sensitivity of Flow Simulation to Permeability ............................................... 53

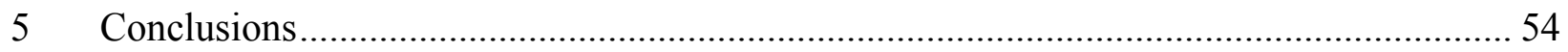

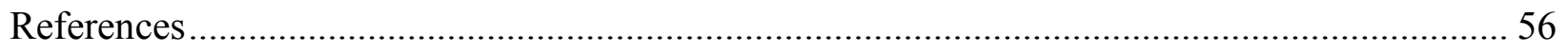

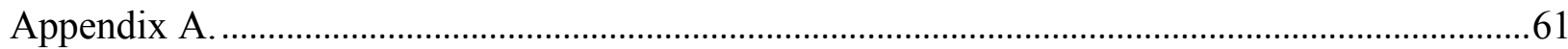

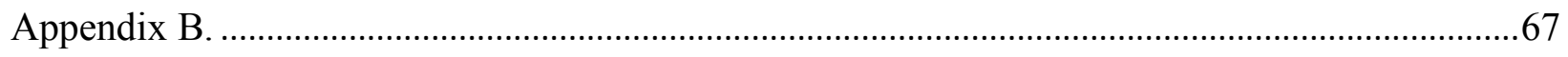




\section{LIST OF TABLES}

Table 3-1: Room Temperature Viscosities of Infusion Resins.............................................. 29

Table 3-2: Average Fitted Values for VI Compressibility Measurement ................................. 38 


\section{LIST OF FIGURES}

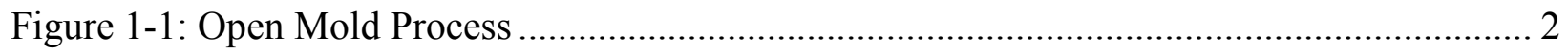

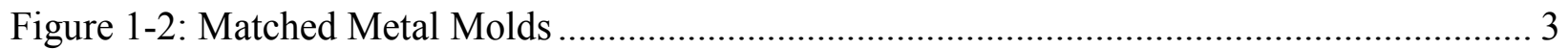

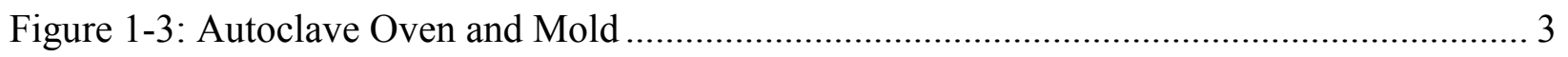

Figure 1-4: Vacuum Infusion Process............................................................................. 4

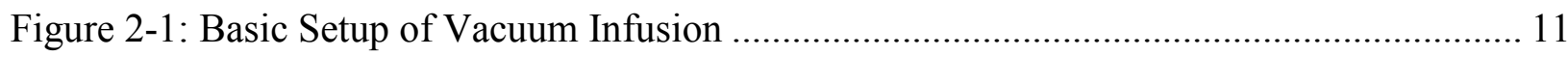

Figure 2-2: RTM-Worx Simulation and Actual Infusion of a Boat Hull .................................... 12

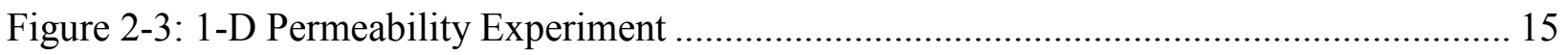

Figure 2-4: Race-Tracking along the Edge of a Mold and Typical Results ................................. 17

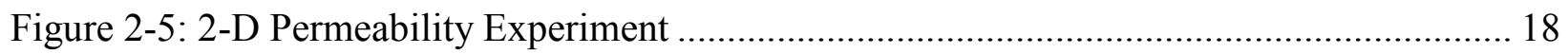

Figure 2-6: Terzaghi Pressure Balance and Thickness Gradient in VI....................................... 24

Figure 2-7: Conservation of Mass in the Constant Thickness (RTM) and Varying Thickness (VI) Processes ................................................................................................ 25

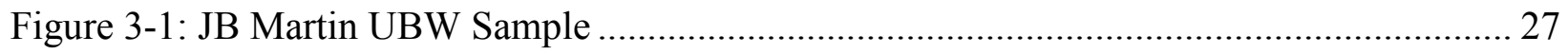

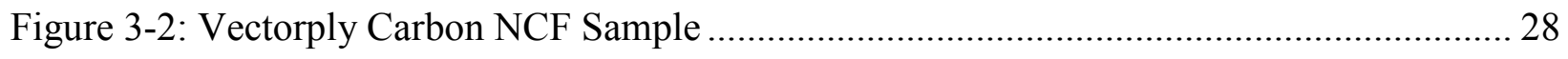

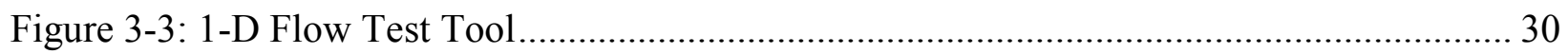

Figure 3-4: Solidworks FEA Showing Tool Deflection ............................................................ 30

Figure 3-5: Second Tool with 3" Thick Acrylic ………………………………………............... 31

Figure 3-6: Reinforcement Sample in 1-D Flow Tool with Silicone Seal................................... 32

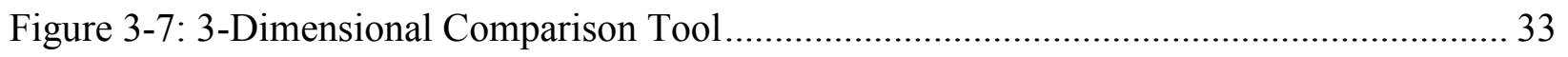

Figure 3-8: VI Test Setup for Continuous Permeability Measurement ......................................... 34

Figure 3-9: Flow Length Measurement through Gap in Speckle Paint Pattern .............................. 36

Figure 3-10: Example Compressibility Curves Determined from Pressure Sensors and DIC during Infusion: (a) Fiberglass UBW and (b) Carbon NCF ……............................... 37 
Figure 3-11: New VI Infusion to Minimize "Noise"

Figure 3-12: Sensitivity of Compressibility $\left(P_{C}\right)$ and Permeability $(K)$ to Initial Thickness Measurement for UBW (left) and NCF (right) in the Warp Direction............................. 41

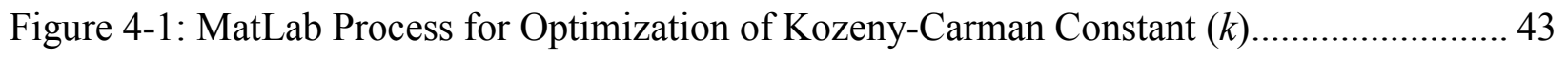

Figure 4-2: Surface Plot of Residual Error in Permeability Fitting ...................................... 45

Figure 4-3: K Fit Sensitivity to Compressibility Model ..................................................... 46

Figure 4-4: Comparison of Average Compressibility Models from Warp and Weft ................ 47

Figure 4-5: Goodness of Fit Comparison for each Infusion Experiment, Arranged by Rows; from Top to Bottom-- Glass UBW Warp, Weft, Carbon NCF Warp, Weft........................ 48

Figure 4-6: $L^{2}(t)$ Measurement (Symbols) and Fit (Dashed Lines) for (a) UBW and (b) NCF Reinforcements 49

Figure 4-7: $K\left(v_{F}\right)$ Plots for All Infusions: (a) Glass UBW and (b) Carbon NCF 50

Figure 4-8: Average Fit of $K\left(v_{F}\right)$ for (a) Glass UBW and (b) Carbon NCF, with Standard Deviation $(\sigma)$ Upper and Lower Bounds; Compared to 1D and 3D Permeability Test Results 51

Figure 4-9: Permeability Data Results from Benchmark Study 52 


\section{INTRODUCTION}

The use of composite materials in the manufacturing of consumer and commercial products has increased substantially over the last few decades. Composite materials are found in a wide range of industries including aerospace, defense, energy, automotive, and building. The estimated value of products made of composites in 2011 is $\$ 55$ billion (Mazumdar 2012). The consumption of composite based products is estimated to reach $\$ 85$ billion in 2017 (Mazumdar 2012). The largest barrier to the growth of the composites industry is the cost to develop and manufacture high-end composite products. It has been projected that a decrease of 30 percent in the cost of composite products would increase potential sales to $\$ 260$ billion in 2017 (Mazumdar 2012).

One of the most widely used methods to manufacture composite products has historically been through the open mold process shown in Figure 1-1 (CompositesOne). This method employs an open cavity mold where the composite (typically fiberglass) is saturated with a resin through means of spraying or spreading. The composite reinforcement is typically compressed with rollers by hand, to remove air voids from the resin and to compress the fibers for better mechanical properties. Some examples of typical products made through the open mold process are showers, hot tubs, truck cabs and fenders, and RV components. 


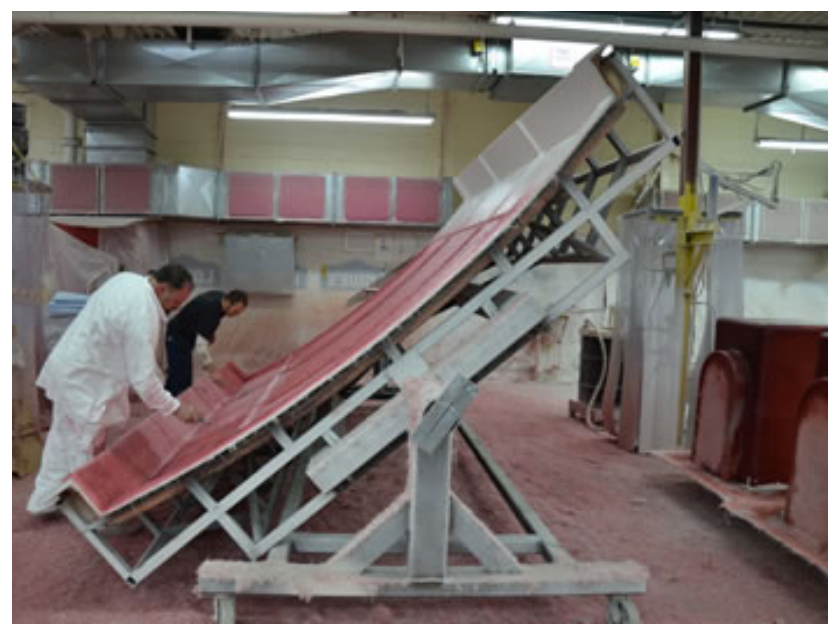

Figure 1-1: Open Mold Process

Open mold processing is generally inexpensive because of the low cost of tooling and materials. One of the problems with using this method is the volatile organic compounds (VOCs) that are released into the atmosphere. VOCs are harmful to operators and can produce both short-term and long-term adverse effects. An additional problem is that it is difficult to achieve high compaction with spraying or rolling the fibers. This results in lower fiber volume fractions, higher resin consumption, and lower strength to weight ratios.

There has been a shift in the composites industry to the closed mold process as a means to control VOCs while still producing high quality parts. Two of the methods used to produce high-end products include processing with matched metal molds shown in Figure 1-2 (Gardiner 2016), composed of an upper and lower mold with a cavity that is the shape of the part being formed, or through the use of an autoclave oven shown in Figure 1-3 (Gates 2016). Both of these methods require extremely expensive tools and machines to produce the end product. 


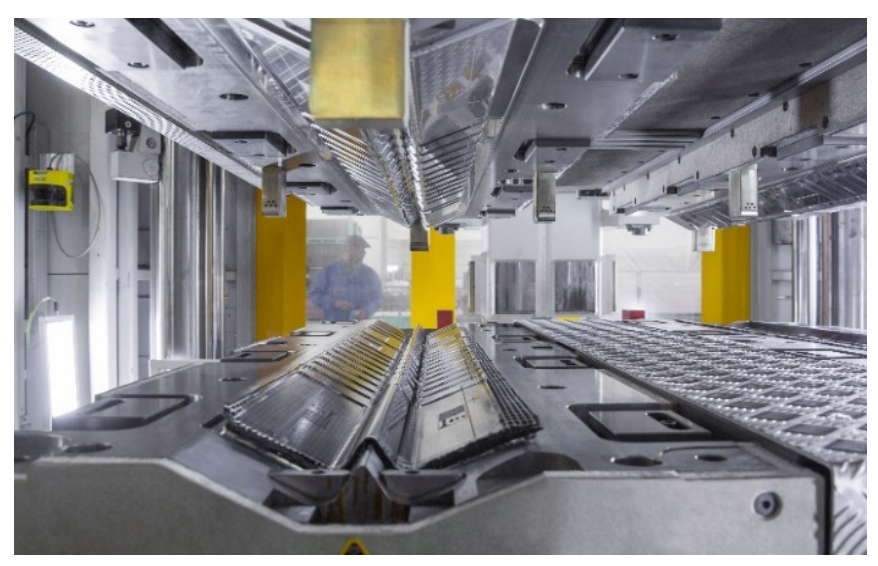

Figure 1-2: Matched Metal Molds

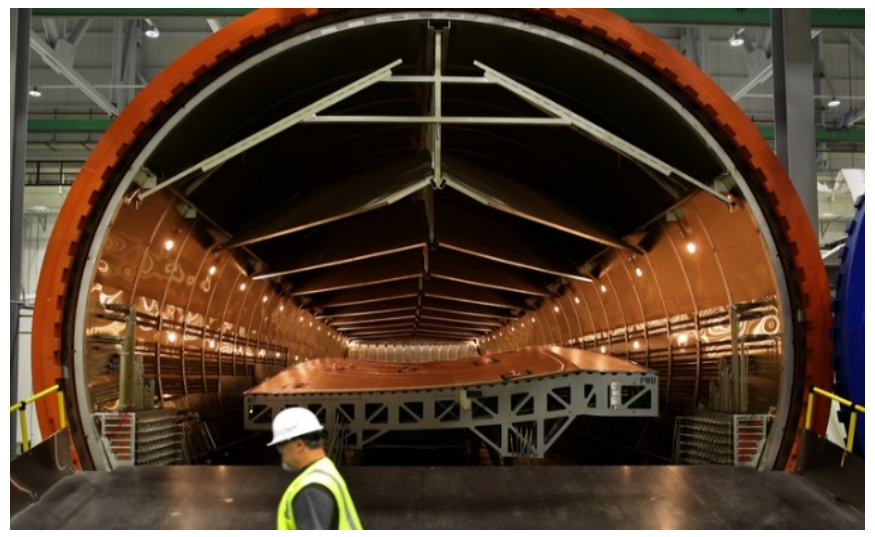

Figure 1-3: Autoclave Oven and Mold

Vacuum infusion (VI) has emerged as an answer to controlling VOCs and achieving high-quality parts without the need for expensive tools and equipment. This method utilizes a one-sided, hard mold (similar to the open mold process) with a flexible membrane that seals to the mold as shown in Figure 1-4 (Johnson 2015). Vacuum is applied to the cavity between the mold and membrane to compact the composite fibers and draw resin through the part being made. The result is a process that is safe, fast, efficient, and relatively inexpensive, while producing a quality part. 


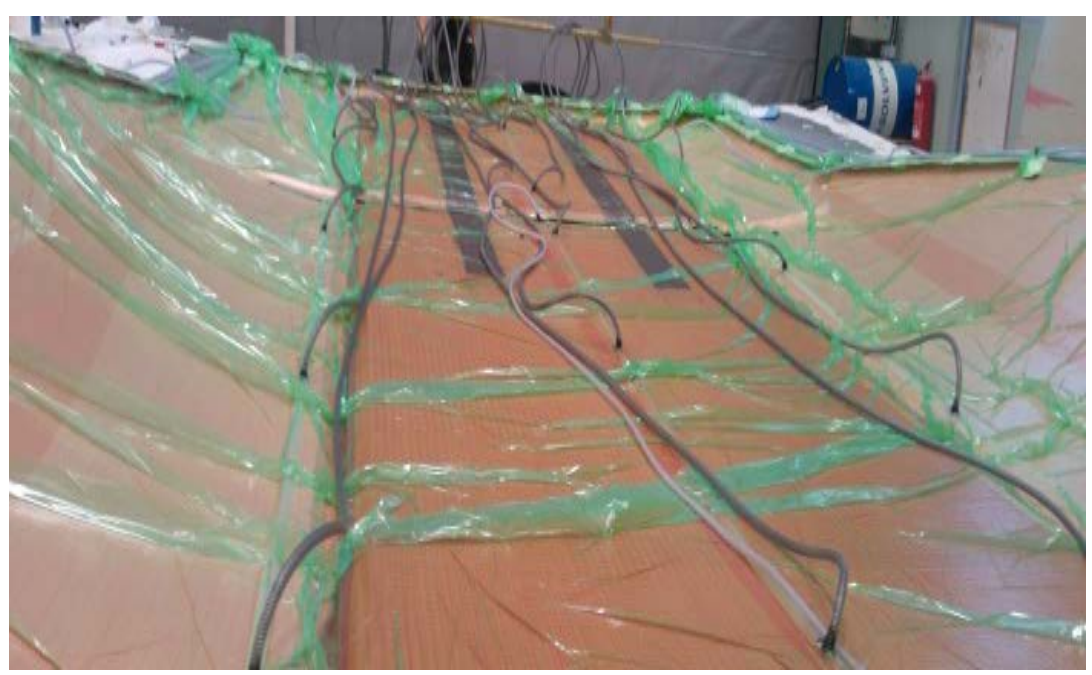

Figure 1-4: Vacuum Infusion Process

One of the hurdles that vacuum infusion has to overcome involves creation of an inexpensive, accurate method to prototype and develop new products. An ideal solution for reducing the expense of costly prototyping entails the use of flow simulation software to predict how the resin will flow through the composite fabric, to quickly and completely fill the part. To accurately model the flow of resin through a part, designers must know the relationship between permeability and fiber orientation/content of the reinforcement fabric. The permeability of a fabric is the quality which allows a liquid to flow through it and the fiber content is the ratio of fabric to resin contained in the part.

Determining the permeability of a fabric usually requires repetitive and time-consuming testing of the material. The testing must be performed for each variation of proposed fabric and at various fiber contents and fiber orientations. Such testing increases the cost of research and development, adding to the cost of the final part. 


\subsection{Problem Statement}

In order to lower the cost of development, and elevate the composites industry to its potential, there needs to be a quick, efficient method to determine the permeability of a fabric throughout a range of fiber volume fractions

\subsection{Research Questions}

To use flow simulation models to expedite manufacturing design, designers need to test the permeability of the reinforcement in various directions and also at various levels of compaction; i.e. they need to determine the relationship between permeability $(K)$ and fiber content $\left(v_{F}\right)$ for a reinforcement. This type of testing is required when process simulation treats the case of a flexible cover (vacuum bag film and reusable silicone bags), as well as when the part geometry dictates non-uniform thicknesses. Traditionally, such permeability data is developed by repeating in-plane permeability tests at different thicknesses with samples having the same number of layers. This can be quite tedious and relies on interpolation, and sometimes extrapolation, to predict the permeability at fiber contents that were not experimentally determined.

This study presents a novel method to rapidly determine the permeability over a continuous range of fiber content values, $K\left(v_{F}\right)$, in a single unidirectional flow experiment. The proposed experiment is a reflection of true industrial application by testing unsaturated flow, the flow of resin through dry fibers. It also eliminates the sealing issues of plunger-type tooling and minimizes the thickness accuracy challenges of radial compression testing. The method generates infusion under a vacuum bag, in which the fluid pressure is monitored by sensors and the thickness gradient across the vacuum bag is measured using digital image correlation (DIC). 
The flow front length is measured at several time increments, and that length vs. time data is compared to the same data predicted by an analytical flow model based on a guess for the empirical fitting constants in the $K\left(v_{F}\right)$ model. Those fitting constants are then iterated until the simulation matches the experimental flow progression data.

\subsection{Hypothesis}

It is hypothesized that permeability values can be obtained for a continuous range of fiber volume fractions in a single infusion test. The result will be a method that is faster and more reliable than previous attempts to obtain permeability values. This method will contribute to the advancement of flow simulation and its use in product development of liquid composite molding processes.

\subsection{Definitions and Terms}

Autoclave- a pressure vessel used to process parts and materials which require exposure to elevated pressure and temperature

Capillary Flow- the preference of a liquid resin to flow around fiber bundles in a reinforcement fabric as opposed to through them

Compaction- the process by which porosity of a composite is decreased as a result of its tows or rovings being squeezed together

Compressibility- the ratio of the amount of compaction pressure that is needed to obtain a desired fiber volume fraction

De-bulking- the process of removing air from a composite layup under a flexible membrane 
Dwell time- the amount of time that a composite layup is held after the de-bulking phase and before injection of the liquid resin

Fiber volume content $\left(v_{F}\right)$ - the volume of fiber divided by the total volume (fiber and resin) of a fiber-reinforced composite material

Flow simulation- a software program that predicts the flow of a liquid resin through a preform of dry reinforcement

Layup- the placement of composite fabrics into a mold, with predetermined number of plies and fiber orientation

Liquid Composite Molding (LCM)- a manufacturing process which consists of a preform of dry reinforcement fibers that is loaded into a mold and then saturated with a liquid resin system

Nesting- the settling of tows or rovings of a fiber reinforcement into the low spots in between tows or rovings of an adjacent fiber reinforcement

Non-crimp fabric (NCF)- multiple layers of unidirectional fibers, with each ply placed in a different orientation, which are typically stitch bonded as opposed to being woven

Out-of-Autoclave (OoA)- manufacturing method which employs methods other than using an autoclave oven to apply elevated pressure and temperature to process a composite part

Permeability $(K)$ - the state or quality of a material that causes it to allow liquids to pass through it 
Preform- a pre-shaped fiber form, whose fibers are arranged in the approximate shape, contour, and thickness desired in the finished composite part

Race-tracking- the rapid flow of resin along a path in the mold in which there is little or no reinforcement fiber filling the cavity

Resin- a liquid polymer that is used to saturate dry reinforcement fibers in a composite part

Resin Transfer Molding (RTM)- a subset of LCM in which resin is transferred into the fabric preform by injection with pressure

Roving- a long and narrow bundle of fibers, typically referring to fiberglass bundles

Saturated Flow- in reference to composites, it is the flow of resin through a reinforcement fabric that has been fully wetted

State of the Art- the level of development (as of a device, procedure, process, technique, or science) reached at any particular time usually as a result of modern methods

Tow- an untwisted bundle of continuous fibers, typically used in reference to bundles of carbon fiber

Unidirectional (UD)- a reinforcement fabric which has tows or rovings oriented in a single direction

Unsaturated Flow- in reference to composites, it is the flow of resin through a dry reinforcement fabric

Volatile Organic Compound (VOC)- organic compounds that easily become vapors or gases which may be harmful to human health or cause harm to the environment 
$P_{A^{-}}$atmospheric pressure

$P_{C^{-}}$compaction pressure

$P_{R^{-}}$resin pressure

$P_{V \text { - vacuum pressure }}$ 


\section{LITERATURE REVIEW}

\subsection{Liquid Composite Molding}

Liquid composite molding (LCM) is a low-cost manufacturing alternative to prepreg processing. LCM is a family of processes which consists of a preform of dry reinforcement fibers that is loaded into a mold and then saturated with a liquid resin system. Three common LCM process are resin transfer molding (RTM), vacuum assisted resin transfer molding (VARTM), and vacuum infusion (VI). The RTM process employs a set of matched metal molds and resin is injected into the mold with pressure, typically in the range of 100-200 PSI. Some of the drawbacks of RTM are expensive tooling, low fiber volume content, and difficulty in predicting flow fronts resulting in dry spots and high void content (Berenberg 2003).

As the name implies, vacuum assisted resin transfer molding uses vacuum at the outlet to assist in the transfer of the resin system through the mold. VARTM frequently uses pressure to also inject the resin into the reinforcement fabric, but lower pressure is typically used than in RTM. VARTM can be used at higher pressures with matched metal molds, medium pressure in light RTM (LRTM), and low pressures under a flexible membrane. When only vacuum is used in the resin transfer process, it is typically referred to as vacuum infusion, and is often considered as a subset of VARTM. 


\subsection{Vacuum Infusion}

When a part is large enough to prohibit autoclave usage and low volume batches will be made, vacuum infusion (VI) is the usual alternative. Vacuum infusion is a common manufacturing process for composite materials, which involves drawing resin through dry fibers under a flexible membrane by way of vacuum suction. Dry fibers are loaded into an open mold and a sealing method is employed, typically double-sided tacky tape, to encapsulate the dry fibers with the flexible membrane. Vacuum is applied to the perimeter, middle, or one side of the layup which communicates a pressure differential through the fabric to an inlet opposite the vacuum. The tube is inserted into a container of resin, and when opened to atmospheric pressure, the resin flows through the composite towards the vacuum source as shown in Fig. 2-1 (Performance Composites Inc.).

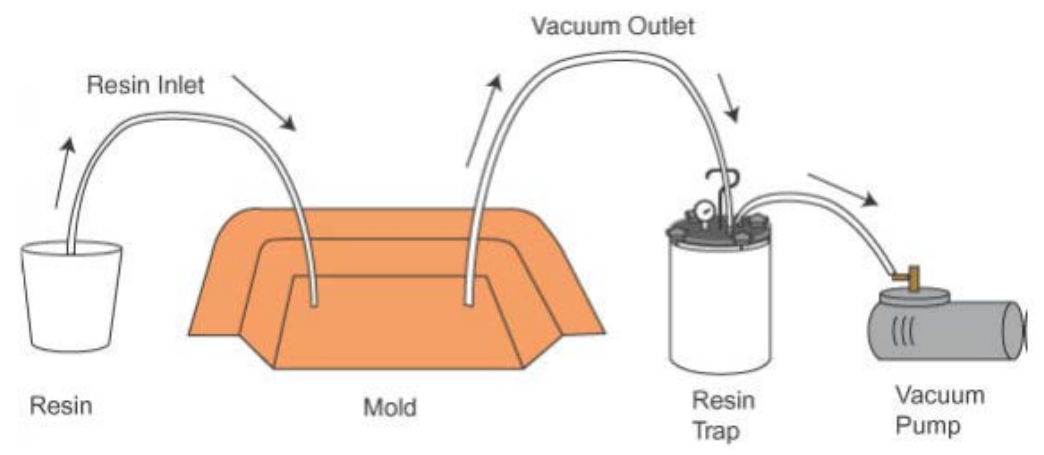

Figure 2-1: Basic Setup of Vacuum Infusion

Variations of VI have been in use since the 1950s, often to reduce styrene emissions from open molding or reduce tooling costs from matched metal molds (Williams 1996). These two benefits have made VI a very practical alternative manufacturing process for large composite parts such as wind turbines, boat hulls, and some aerospace structural components. Vacuum infusion is typically chosen when the part size makes autoclave processing prohibitively 
expensive and is often utilized on low volume production runs. With a frequent need to optimize the process for new part geometries, and little time or resources for prototyping, flow simulation has benefitted those manufacturing with VI (Koorevaar 2002).

\subsection{Benefits of Flow Simulation}

When designing an LCM manufacturing process, flow simulation is often used to assist in mold design and to enable faster product-to-market transition by shortening the development process. Flow simulation can help you determine the optimal location for the injection port(s), vent(s), and feed lines (Koorevaar 2002). Figure 2-2 (Polyworx 1999) demonstrates the simulation and filling progression of a Conyplex Contest 55 boat hull. The simulation software can also determine filling time to determine the correct resin system; gel time and cure time are crucial to achieve a full fill, especially when processing large, expensive parts.

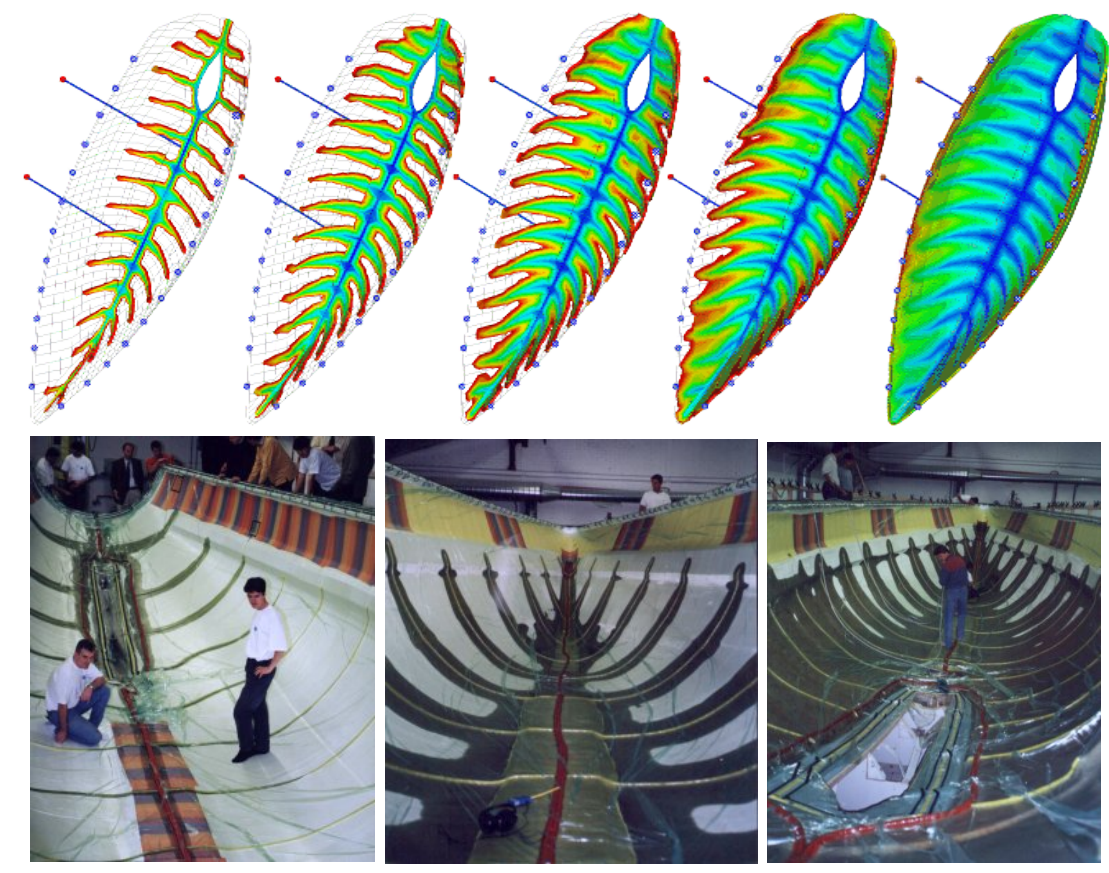

Figure 2-2: RTM-Worx Simulation and Actual Infusion of a Boat Hull 
The knowledge provided by simulation software can be invaluable when there is limited time to start tooling construction or when trial and error methods would prove cost prohibitive (Koorevaar 2003). Utilization of flow simulation can also help increase the likelihood of a completing a successful part on the first try. This knowledge can be a great source of confidence when prototyping parts such as boat hulls, which can have material costs in the $\$ 100,000$ s.

Flow simulation is heavily reliant on the input of accurate information. If the information used to simulate the filling of a new part is not correct, there is a low probability of accurately predicting the optimal locations for ports, vents, and feedlines. One of the important data inputs in flow simulation is permeability $(K)$.

\subsection{Permeability Testing}

Flow simulation for LCM is commonly based on Darcy's Law, which requires the permeability of the reinforcement material to be characterized. The permeability is a function of the reinforcement architecture and is the inverse of the resistance to flow. The permeability is usually highest along the direction of the fibers, but due to the common laminate structure with plies of varying fiber orientations, the resin flow must also flow against the fibers in many areas of a composite part. One must thus test the permeability of the reinforcement in various directions.

There have been several methods proposed to measure permeability and fiber volume content $\left(v_{F}\right)$. Most of these procedures involve compressing the composite between two hard plates to achieve the desired laminate thickness. This amount of compaction determines the fiber volume content, since there is a fixed amount of space for the reinforcement material and the remaining space is available for the resin to occupy. A test fluid, that represents the resin, is then 
injected into the mold at the inlet. The data that is typically collected is injection pressure, fluid pressure in the part, and fluid flow rate. Permeability components are derived using the data collected during observation (George 2011).

Many component designs call for varying part thicknesses which can cause deviations in the local fiber volume content. The flexible tooling used in vacuum infusion (VI) causes a thickness gradient across the part during processing, also entailing a gradient in $v_{F}$. Both of these cases involve a change in fabric architecture. Thus for these two cases, the permeability must also be measured at various levels of compaction, to determine the relationship between permeability and fiber content for a reinforcement.

When the permeability has been evaluated at multiple values of $v_{F}$ it is commonly fit to either a power-law model (Joubaud 2005):

$$
K=A_{k} v_{F}^{B_{k}}
$$

Or the Kozeny-Carman equation (Carman 1997):

$$
K=k \frac{\left(1-v_{F}\right)^{3}}{v_{F}^{2}}
$$

There are several methods currently in the state of the art to measure permeability of a composite fabric. These methods can be categorized by the dimensionality of flow. They are usually referenced by the number of permeability components they analyze in a single test. Most methods fall under one of two categories: unidirectional flow (1-D) or radial flow (2-D) (George 2011). 


\subsection{1-Dimensional In-Plane Testing Methods}

The first permeability measurements were based on Darcy's original experiments of flow through sand. These experiments are considered "saturated" flow because the fibers have been completely wetted and the amount of fluid is measured over a period of time to determine the flow rate. Current LCM processes involve flowing a resin through dry fibers, so the 1D experiment was adapted to measure the flow front through unsaturated media. Unsaturated flow testing involves injecting the test fluid on one end of the fabric and the flow front is measured as it progresses to the outlet as shown in Figure 2-3 (Parnas 1995). The data is plotted as a function of length and time and is used to calculate the permeability. This latter method is accepted as being more genuine to the LCM process, since it involves wetting flow of a dry reinforcement. However, this method introduces some complications to flow progression such as capillary flow between the tows or rovings of the typical composite reinforcement fabric.

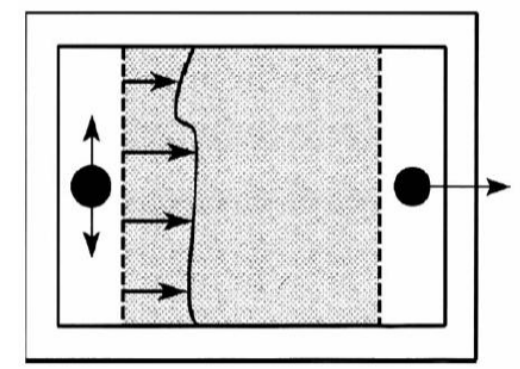

Figure 2-3: 1-D Permeability Experiment

An experimentation method was patented where the permeability through a stack of felt was determined by measuring the pressure difference across the flow path (Stedile 1971). The method was then modified to measure the permeability of continuous, aligned fibers which is more typical of composite reinforcement (Williams 1974). An empirical solution for 
measurements in various flow orientations was proposed by Martin and Son (Martin 1986).

Saturated flow tests were also introduced, to evaluate the permeability independent of the wetting effects (Pan 2000). To reduce the number of tests required to characterize the permeability in all in-plane fiber orientations, Gebart and Lidström (Gebart 1996) developed a "multi-cavity unidirectional experiment," where samples in four different fiber orientations are evaluated in a single experiment.

A worldwide benchmark was organized, where the same reinforcement was measured by several research institutions using unsaturated 1-D flow experiments, in which the measurement results varied by multiple orders of magnitude between labs (Arbter 2011). A second worldwide benchmark exercise was organized, in which a detailed methodology was prescribed to all the participants, and the resulting scatter in permeability measurements between labs was approximately equal to the scatter for a given lab's replicate measurements (Vernet 2014). The intra-lab and inter-lab standard deviation was approximately $25 \%$, which has been accepted as an approximate minimum in precision for permeability measurement. This minimum degree of scatter is due to the small variation in reinforcement geometry from point to point in the sample and race-tracking.

One of the greatest challenges in 1D flow testing is the occurrence of race-tracking. Race-tracking is the rapid flow of the resin along a path in the mold in which there is no reinforcement fiber (Buntain 2003) and typically occurs where the reinforcement fabric isn't tight against the edge of the mold. Figure 2-4 (Lawrence 2002) demonstrates this phenomenon, which can cause errors of as much as $100 \%$ in permeability measurement (Parnas 1997); its magnitude is unpredictable and unrepeatable (Devillard 2003). The best strategy to reduce the 
risk of race-tracking is to ensure that the fabric is cut to accurate dimensions. Other methods employed are to apply tacky tape tight against the edge of the material or use a silicone seal.

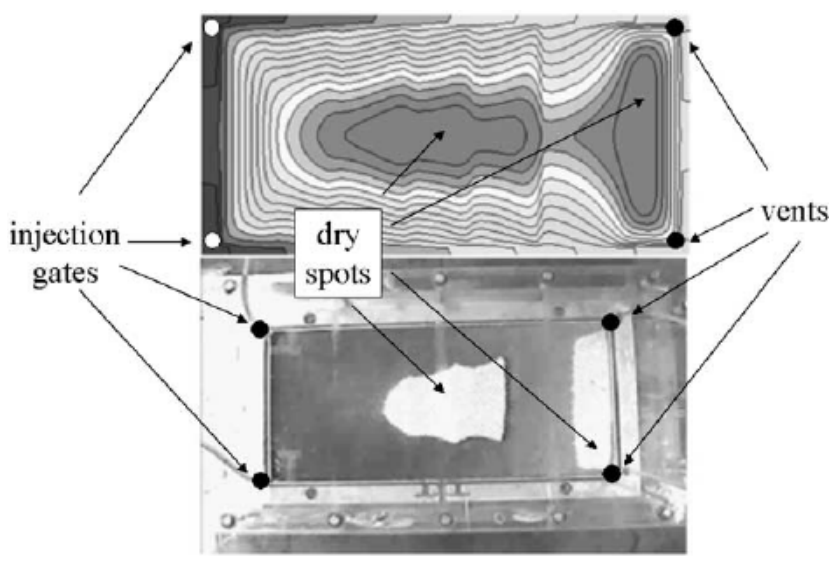

Figure 2-4: Race-Tracking along the Edge of a Mold and Typical Results

\subsection{2-Dimensional In-Plane Testing Methods}

The problem of race-tracking in 1-D testing, as well as the need to perform multiple experiments required to calculate permeability in both warp and weft directions, led directly to radial experimentation (Gonzalez 1983). Figure 2-5 (Parnas 1995) demonstrates this technique where the resin inlet is in the center of the reinforcement and flows outward towards the edges. This reduces race-tracking along the side edges because it is the last portion of the fabric to be saturated. It is still possible to occur, but its effects are minimized due to the fact that the majority of the data is collected by the time the resin reaches the edges. Adams, et al. proposed a method to determine both warp and weft directions of the in-plane permeability from only one radial experiment (Adams 1986). Since only one sample is required to determine permeability in both directions, both preparation time and experimentation time are decreased compared to 1D testing. 


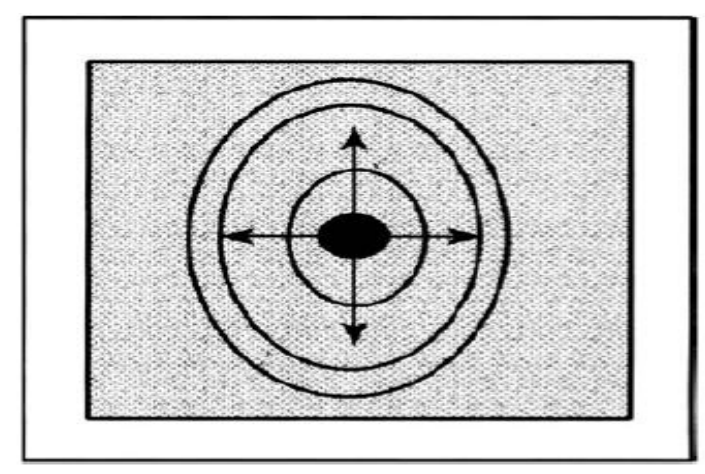

Figure 2-5: 2-D Permeability Experiment

A disadvantage of the 2D method is that the material and the flow front have to be visible through the entire process. In contrast, 1-D testing can be done by visually monitoring the flow front, as well as by measuring the flow rate of the resin in a saturated test. In order to measure the flow front, a clear plastic, such as acrylic, is typically used on one side of the mold. Most transparent mold materials have a relatively low stiffness in comparison to the rest of the mold, which is usually metal. The surface area of the mold used to perform 2-D testing is generally larger than that used in 1-D testing because it typically needs to be as wide as it is long to measure both directions. Because of this requirement, mold deflection is a common challenge to radial flow tests. At an injection pressure of 3 bars, the deflection of a PMMA cover at the center of a large radial flow mold was observed to be about $30 \%$ of the cavity thickness (Gebart 1996). Errors in permeability measurement have been attributed to such mold deflection (Parnas 1997). Mold deflection can be limited by placing a stiff metal frame over the top of the transparent mold side, but doing so decreases visibility of the flow front.

The results from 1-D and 2-D test methods were compared in previous studies in which the differences between the two methods were attributed to such mold deflection in the radial testing (Parnas 1993). 


\subsection{3-Dimensional Testing Method}

Another method for permeability characterization is by point-infusion into the top of a stack of material. A mathematical solution exists for calculation of the permeability given the shape of an ellipsoidal flow front in such three-dimensional flow (George 2014). The flow geometry at the point the resin reaches the bottom of the mold can be measured and is used for such calculation. This method produces measurements for all three components of the diagonalized permeability tensor in one test but requires a significant effort in setup time to achieve one data point for permeability measurement.

\subsection{Continuous Permeability Measurement Methods}

As already mentioned, for any component with varying values of $v_{F}$ requires that the permeability be evaluated for the range in $v_{F}$. Traditionally, such a model for $K\left(v_{F}\right)$ is developed by repeating permeability tests at different thicknesses with samples having the same length, width and number of layers (Vernet 2014). This can be quite tedious and relies on interpolation and sometimes extrapolation to predict the permeability at fiber contents that were not experimentally determined. To reduce the required amount of experimentation time, and to potentially eliminate the need for interpolation, various studies have proposed methods to measure the permeability of a reinforcement for multiple values of, or even a continuous range of $v_{F}$ in a single experiment. The latter case has been called "continuous" measurement of the permeability.

Stadtfeld et al., developed a plunger-type mold for in-plane permeability measurement, in which a hydraulic piston expanded the mold cavity while performing a unidirectional flow test (Stadtfeld 2002). The pressure drop was measured from the inlet to the vent, to compute the 
permeability as $v_{F}$ decreased. This is perhaps the first continuous permeability measurement method, i.e., where $K$ can be determined at a range of $v_{F}$ values from a single flow test. The authors detailed a sealing method for such a mold, but achieving an adequate seal which allows the cavity height to also be adjusted is still thought to be a challenge. Experimental results were only presented for two flow tests. Although fair agreement was seen between multiple tests on the same sample, this is prone to the "debulking" effect where the fabric architecture, and thus the permeability, changes with repeated compression (Robitaille 1999, Saunders 1999). No permeability results from alternative measurement methods were presented to validate this approach.

Unidirectional flow tests have also been performed in which the $v_{F}$ was varied along the flow path by modifying the ply count, i.e., adding small sections of extra material to certain sections along the flow path (Di Fratta 2015). A mathematical model was developed to determine the permeability for each of the sections, requiring a pressure sensor at the inlet and another somewhere along the flow path. Good agreement was seen between the permeability measurements of three $v_{F}$ values in a single test compared to those same $v_{F}$ values measured in three separate unidirectional tests. A suggested application would be to put both warp and weft orientation samples in the mold, allowing calculation of the warp and weft permeability ( $K_{x}$ and $K_{y}$ ) in a single test. This method is not fully continuous, however, as one must choose discrete values in $v_{F}$ to test. Very little instrumentation is required, but this method seems to generate a significant amount of experimental noise because all of the results depend on a single pressure sensor away from the flow front.

The through-thickness permeability $\left(K_{z}\right)$ has been measured during transverse unidirectional flow through a stack of the material. This has been implemented in a plunger-type 
tool similar to that mentioned above, enabling continuous measurement of $K_{z}$ for a range of $v_{F}$ (Scholz 2007, Comas-Cardona 2007, Ouagne 2010). Race-tracking is a common challenge in one-dimensional flow measurement for both in-plane and transverse methods (Scholz 2007, Wu 1994).

A later continuous permeability measurement method was presented for in-plane radial flow during unidirectional transverse compression testing (Buntain 2003). The fluid pressure at the center of the sample was measured with a pressure sensor while the wetted sample was squeezed, allowing for continual $K$ measurement from Darcy's Law for radial flow and the Terzaghi equation (Terzaghi 1996). A related radial method was presented, in which two wet unidirectional compression tests were performed, one on plane tooling and the other on a perforated platen which allows for through-thickness flow and minimizes the fluid pressure buildup (Comas-Cardona 2007). The latter test allows determination of the compressibility, i.e., the compaction pressure as a function of $v_{F}$. This allows determination of the fluid pressure in the former test, using Terzaghi's equation, so that the continuous radial permeability may be calculated as in the above-mentioned study. Although requiring a second test, this method needs no measurement of the fluid pressure, and also allows estimation of the through-thickness permeability. Optimization of the perforation sizes is thought to be necessary to minimize fluid pressure buildup, yet not cause stress concentration between the fiber bridging. Radial flow is assumed to prevent the common problem of race-tracking in unidirectional flow testing, but both of these radial flow methods showed permeability results significantly higher than results from traditional one-dimensional testing. The error was attributed to compression tool deflection (Buntain 2003) and thickness precision problems (Comas-Cardona 2007). 
Another radial flow approach adds a third compression test to the last-mentioned study, with a rectangular tool being oriented in first the warp and then the weft directions for the two non-perforated tests (Martin 2016). This allows concurrent measurement of $K_{x}$ and $K_{y}$, by iterating them in a numerical flow simulation until the predicted pressures match those calculated from the experiment.

The continuous permeability measurement methods above are all based on saturated flow. While saturated flow measurements are more repeatable and not influenced as much by capillary forces, they are not as representative of industrial infusion, where flow simulation must capture the movement of the flow front through the reinforcement (Pillai 2004).

As stated before, this study presents a method of determining the permeability over a continuous range of fiber content values in a single unidirectional flow experiment. The process is done via unsaturated flow to better reflect the industrial process of LCM, eliminates the sealing issues of plunger-type tooling, and minimizes thickness accuracy challenges. The vacuum infusion is done under a flexible bag, while fluid pressure is monitored by sensors and the thickness gradient across the vacuum bag is measured using digital image correlation (DIC). The length vs. time data is then compared to the data predicted by an analytical flow model.

\subsection{Analytical Flow Model}

Most flow models are based on Darcy's Law for flow in porous media, and require an understanding of the pressure gradients. In VI the flow is driven by the difference in pressure between the resin pot, usually left at atmospheric pressure, and the vacuum pressure applied to the mold vent. This is similar to resin transfer molding (RTM) in matched-metal tooling, where the pressure differential from inlet to vent drives the flow. A key difference between RTM and 
VI is the shape of the pressure gradient between the inlet and vent, caused by the flexible tooling (N. Correia 2004, D. M. Modi 2009). Modeling the unique pressure gradient in VI involves application of Terzaghi's Law (Terzaghi 1996), where the flexible membrane, often a vacuum bag, is the interface between opposing pressures in equilibrium. Atmospheric pressure $\left(P_{A}\right)$ acts on the top of the bag, and the sum of the vacuum pressure $\left(P_{V}\right)$, resin pressure $\left(P_{R}\right)$, and compaction pressure on the reinforcement $\left(P_{C}\right)$ act on the underside of the membrane:

$$
P_{A}=P_{V}+P_{R}+P_{C}
$$

In the case of dry fibers, the difference between atmospheric and vacuum pressure is fully applied as compaction pressure on the reinforcement. The fibers behave like springs and compress under vacuum pressure until the compaction pressure balances the other pressures to achieve a balanced thickness. When the resin inlet is opened into the vacuumed mold, infusion begins and surrounds the fibers with resin. As the resin comes in at ambient pressure (from the pot), and vacuum pressure exists in the mold, a pressure gradient develops because of the porous media, similar to Reynolds Law for flow in a pipe. As the flow front progresses through the mold, the resin pressure at any spot behind the flow front continually increases, and this pressure pushes back on the bag. Because the atmosphere-to-vacuum pressure ratio remains the same, Terzaghi's Law tells us that the increasing resin pressure reduces the compaction pressure and the fibers expand, which raises the bag as demonstrated in Figure 2-6. The difference in thickness $(h)$ during the infusion arises from the dependency of the local pressure gradient on itself; the increase in $P_{R}$ causes a local increase in porosity, which in turn reduces the pressure gradient at that location. 


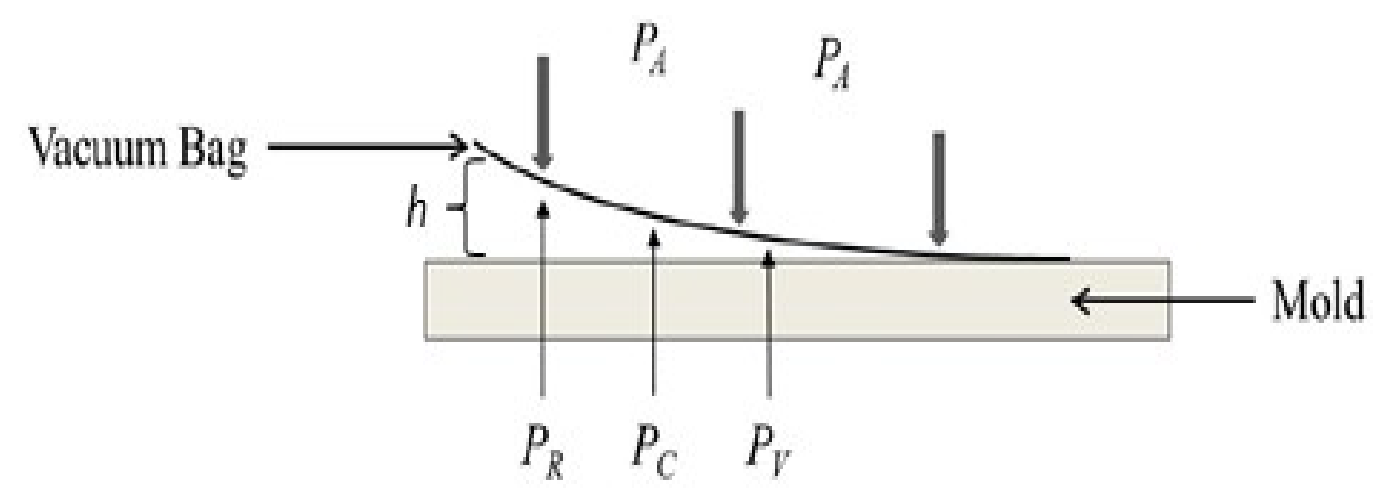

Figure 2-6: Terzaghi Pressure Balance and Thickness Gradient in VI

Several analytical solutions have been presented to model the flow, which account for the thickness $(h)$ variation of the reinforcement that occurs during vacuum infusion. Correia developed a model for unidirectional constant flow rate (Correia 2005), by using a nondimensionalized flow front position, $\alpha$, to evaluate the pressure gradient, where $\alpha=x / L$. Equation 2-4 builds on Modi's model (Modi 2008):

$$
-\left[\frac{1}{h}-\left(\frac{\alpha}{[h]_{\alpha=1}}\right) \frac{\mathrm{d} h}{\mathrm{~d} P}+\frac{1}{K} \frac{\mathrm{d} K}{\mathrm{~d} P}\right]\left(\frac{\mathrm{d} P}{\mathrm{~d} \alpha}\right)^{2}=\frac{\mathrm{d}^{2} P}{\mathrm{~d} \alpha^{2}}
$$

Figure 2-7 demonstrates Modi's concept of flow through a variable thickness where $\Delta h$ represents the change in height of the fabric thickness during the infusion process, $L$ is the length of the flow front, and $x$ is any position along the infusion path. So, the infusion inlet is located at $\alpha=0$ and $\alpha=1$ is the position of the flow front at any given time during the infusion process (Modi 2008). 

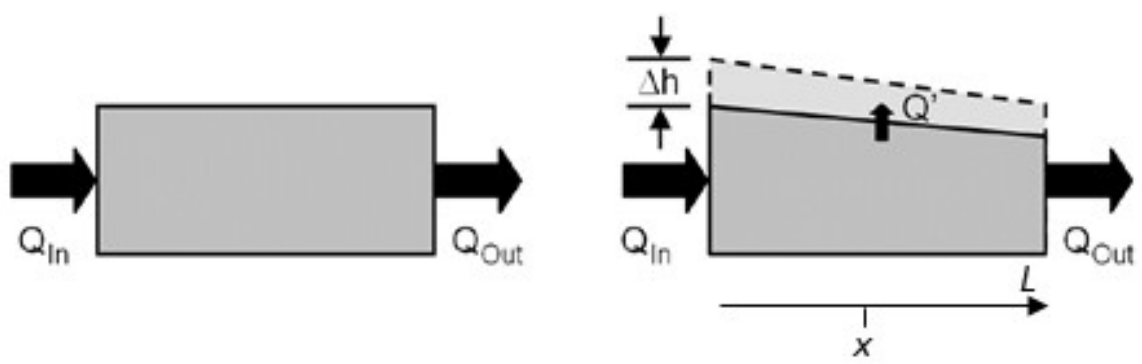

Figure 2-7: Conservation of Mass in the Constant Thickness (RTM) and Varying Thickness (VI) Processes

Modi used the non-dimensionalized $\alpha$, and adapted Correia's solution for a variable flow rate, and detailed the analytical methodology to utilize such a model (Modi 2008):

$$
\frac{\mathrm{d}^{2} P_{R}}{\mathrm{~d} \alpha^{2}}+\left[\frac{1}{K} \frac{\mathrm{d} K}{\mathrm{~d} P_{R}}+\left(\frac{1-v_{F}+\alpha^{2}}{h\left(1-v_{F}\right)}\right) \frac{\mathrm{d} h}{\mathrm{~d} P_{R}}\right]\left(\frac{\mathrm{d} P_{R}}{\mathrm{~d} \alpha}\right)^{2}=0
$$

Given the permeability $\left(K\left(v_{F}\right)\right)$ from the chosen model (Power Law or Kozeny-Carman Equation, Equations 2-1 and 2-2) and compressibility $\left(P_{C}\left(v_{F}\right)\right)$ of the fabrics (related to $P_{R}$ through Equation 2-3), $\mathrm{d} P_{R} / \mathrm{d} \alpha$ may be evaluated using Equation 2-5. Using Darcy's Law:

$$
\frac{\mathrm{d} \alpha}{\mathrm{d} t}=\frac{K}{\mu\left(1-v_{F}\right)} \frac{\mathrm{d} P_{R}}{\mathrm{~d} \alpha}
$$

with the resulting pressure gradient yields a predicted flow front length $(L)$ with respect to time ( ) (Modi 2008). 


\section{METHODOLOGY}

This thesis aims to build on the concepts and methods outlined in the previous chapter to measure the permeability $\left(P_{R}\right)$ of a fabric through the full range of fiber volume contents $\left(\mathrm{v}_{\mathrm{F}}\right)$ in one continuous vacuum infusion test. Similar to previous methods, the experiment employs transducers to measure the resin pressure during the infusion process. The novel way in which the range of fiber volume contents will be determined is by performing the infusions under a flexible membrane and using digital image correlation (DIC) to simultaneously capture the thickness of the fabric.

In this study, several measurements were made of $(L, t)$ during each infusion experiment. The compressibility of the fabric $\left(P_{C}\right)$ is determined by measuring the resin pressure $\left(P_{R}\right)$ with multiple transducers. The fiber volume is calculated from the fabric thickness $(h)$ that is captured using digital image correlation. Then Eq. 5 is used to fit the permeability model by reducing the sum of the square of the residuals between the experimental and predicted times for each recorded value of $L$. The "inverse estimation" of the permeability, i.e. iterating $K$ in flow

simulation until experimental conditions are matched, has been used previously (Comas-Cardona 2007, Wu 1994, Gokce 2005, Alms 2010). 


\subsection{Materials}

\subsubsection{Fabric}

Two reinforcement fabrics were characterized in the study: 1) a fiberglass unbalanced weave (UBW) (JB Martin TG-15-N), and 2) a carbon biaxial non-crimped fabric (NCF) (VectorPly C-BX 1800). The JB Martin fabric is a $15.3 \mathrm{oz} / \mathrm{yd}^{2}\left(518 \mathrm{~g} / \mathrm{m}^{2}\right)$ plain weave fiberglass. It consists of $98.95 \%$ glass and $1.05 \%$ Sapona polyester fabric in the weft direction as seen in Figure 3-1. Special care had to be taken when cutting the sample pieces as the loose nature of the weave and lack of stitching made it easy to lose rovings. If rovings are lost off the side, it would lend to potential race-tracking and errors in data. A point to note is that the larger spacing in the weft direction increases the potential porosity of the fabric and thus capillary flow will be greater in these samples, resulting in greater potential permeability values. Also, the occurrence of nesting can cause greater variation in permeability, increasing the standard deviation between samples.

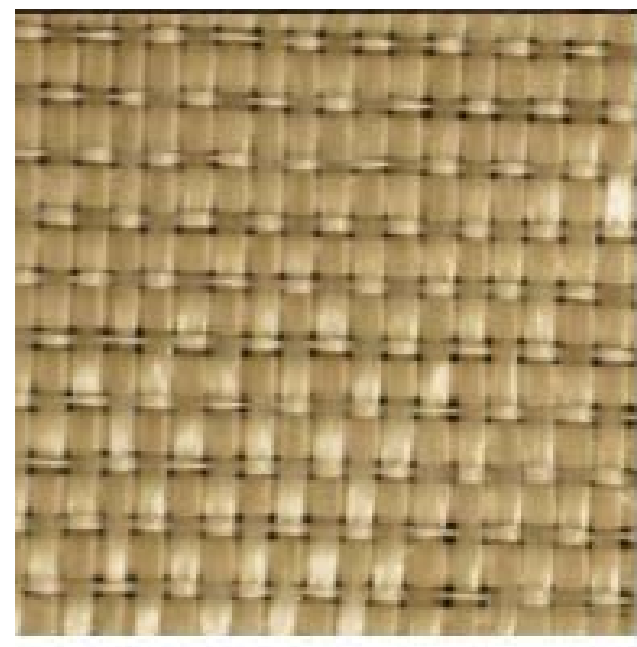

Figure 3-1: JB Martin UBW sample 
The biaxial NCF from Vectorply is a $18.37 \mathrm{oz} / \mathrm{yd}^{2}\left(623 \mathrm{~g} / \mathrm{m}^{2}\right)$ carbon fiber reinforcement with tows running in the $+45 /-45$ directions shown in Figure 3-2. It is a double bias architecture, which means the 45 and -45 reinforcements are equal. The presence of stitching makes cutting accurate, consistent samples easier, decreasing the chance of race-tracking. The tight spacing of the tows limits material porosity, which should yield more accurate permeability data.

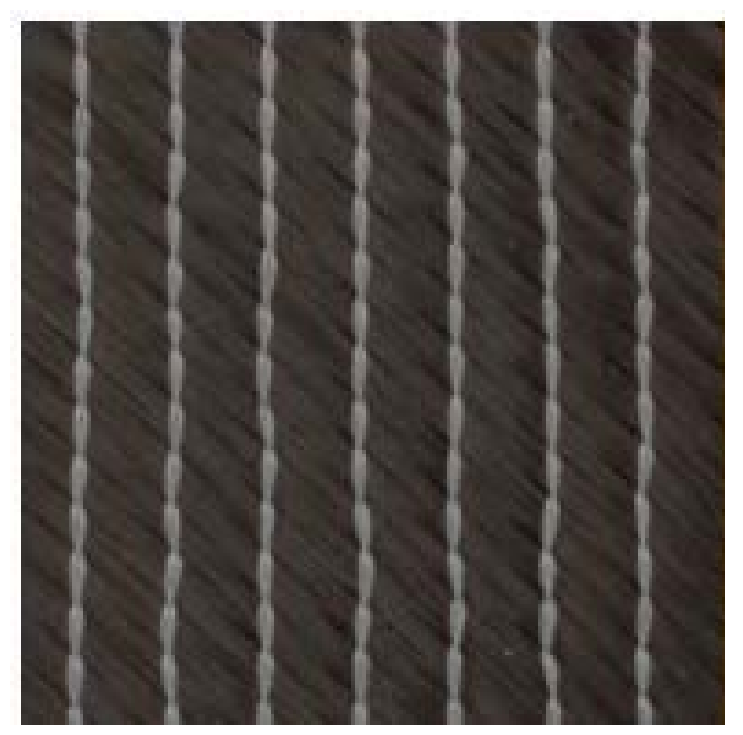

Figure 3-2: Vectorply Carbon NCF Sample

\subsubsection{Resin}

All tests were performed with canola oil due to its similar viscosity $(\sim 0.06 \mathrm{~Pa} \cdot \mathrm{s}$ at ambient temperature), surface tension $(0.033 \mathrm{~N} / \mathrm{m})$, and chemical structure to many thermoset infusion resins listed in Table 3-1. Canola oil was also chosen because of the inexpensive cost, lower skin irritation, ease of clean up, and minimal chance of sensor interference. Although not a resin, $P_{R}$ will remain the designation for pressure supplied by the liquid oil in all tests. 
Table 3-1: Room Temperature Viscosities of Infusion Resins

\begin{tabular}{|c|c|c|}
\hline Resin & $\begin{array}{c}\text { Viscosity } \\
(c P)\end{array}$ & $\begin{array}{c}\text { Viscosity } \\
(\text { Pa } s)\end{array}$ \\
\hline $\begin{array}{c}\text { Proxima polydicyclopentadiene } \\
\text { (pDCPD) }\end{array}$ & $10-20$ & $.01-.02$ \\
\hline Axson RSF 816 & 167 & .167 \\
\hline AOC Hydropel R049-TPF-13 & 105 & .105 \\
\hline CCP 8086 & 85 & .085 \\
\hline Canola Oil & 60 & .06 \\
\hline
\end{tabular}

\subsection{Tooling}

\subsubsection{1-Dimensional Comparison Tool}

In order to compare the permeability values of the continuous permeability measurement method, it was necessary to create a tool which allowed measurement of the permeability at separate fiber volume contents. The objective of the tool was to measure one-dimensional permeability in both warp and weft (in-plane) to compare to data obtained through the DIC/DAQ vacuum infusion testing. The requirements were that it be quick and easy to set up with high repeatability. This 1-D flow test tool was patterned after the one designed by Alms et al. for the second worldwide benchmark exercise (Vernet 2014).

The first tool consisted of a lower plate made of $1 / 2$ " thick steel and an upper plate made of 1" thick acrylic shown in Figure 3-3. Acrylic was chosen for its high visibility, low cost, and relative strength. The plates were bolted together with Grade 8 bolts and C-channel was utilized to distribute the compressive force evenly over the acrylic plate. 


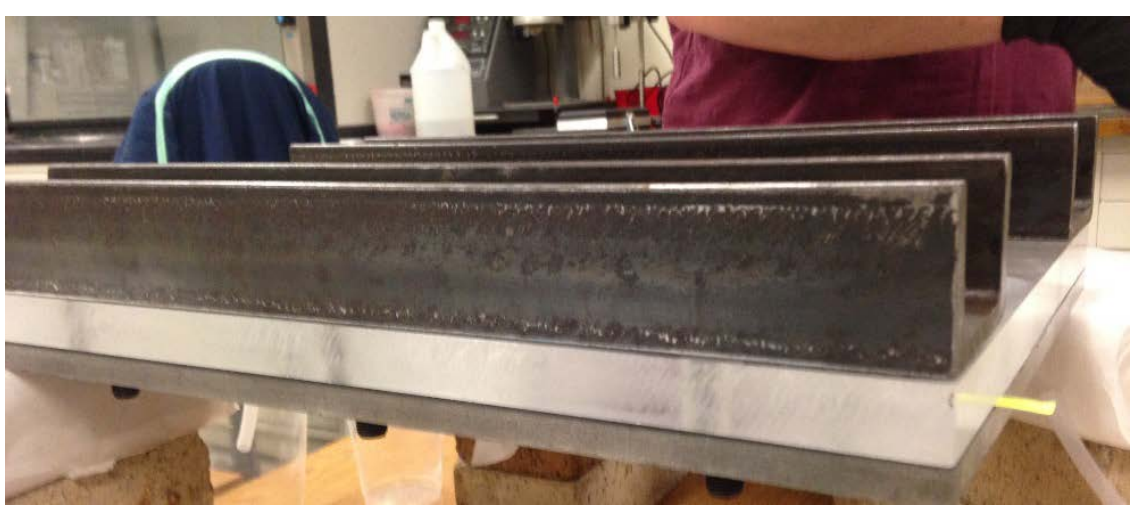

Figure 3-3: 1-D Flow Test Tool

The requirements of the two plates were that they deflect no more than $2 \%$ of the sample thickness at a maximum of 2 bar. It was calculated that $0.04 \mathrm{~mm}$ is the maximum deflection threshold for both the steel and acrylic plates. Figure 3-4 shows the Solidworks model which was used to analyze the deflection of each material to determine an adequate thickness. The thickness of 1 " for the acrylic was determined to be adequate to achieve a maximum of $2 \%$ deflection.
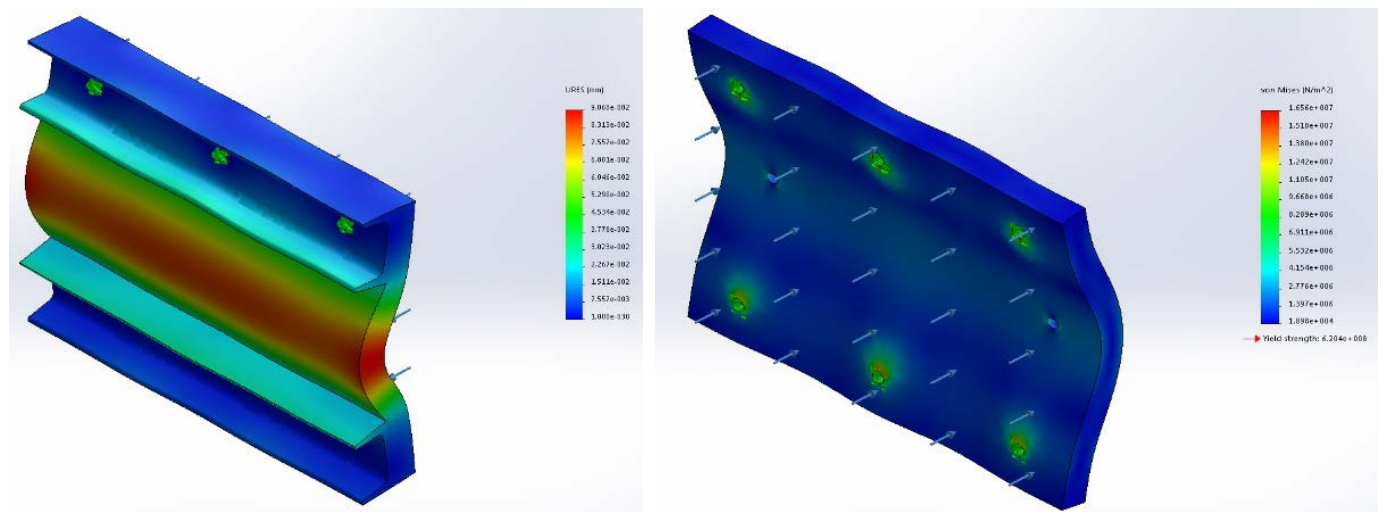

Figure 3-4: Solidworks FEA Showing Tool Deflection

After completing a series of tests, it was determined that there was some race-tracking occurring over the top of the fabric due to tool deflection. It was determined that the acrylic 
plate was deflecting too much due to an error in the model calculations. After further inspection it was decided that the plate had a non-uniform thickness which was determined by measuring various spots across the surface. The Solidworks model was corrected and rerun and it was decided that a 3" plate would provide the desired deflection limits. Figure 3-5 shows the new tool setup with the thicker plate. Technical drawings of the tool components are included in Appendix A. Additionally, the acrylic plate was machined to ensure flatness across the entire plane to avoid the occurrence of race-tracking in low fiber volume samples.

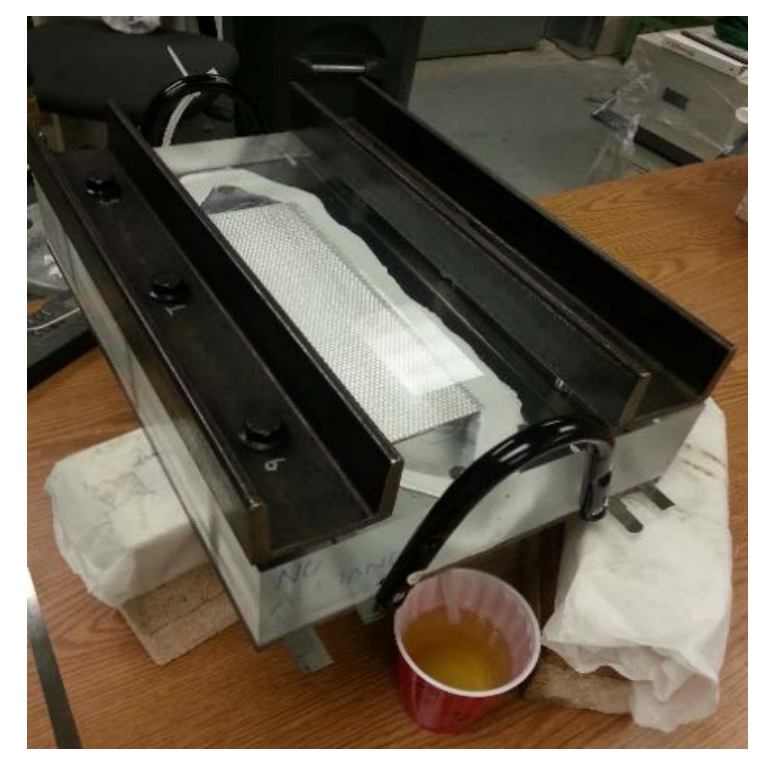

Figure 3-5: Second Tool with 3" Thick Acrylic

An RTV silicone bead was placed around the perimeter of the test area and allowed to cure with calibration shims to ensure uniform thickness. The bead was spaced to the width of the test material and narrowed to the inlet and outlet at each end of the flow direction, as seen in Figure 3-6. The RTV bead provided an adequate seal for infusion testing of various thicknesses without the need to change the seal for each test. 


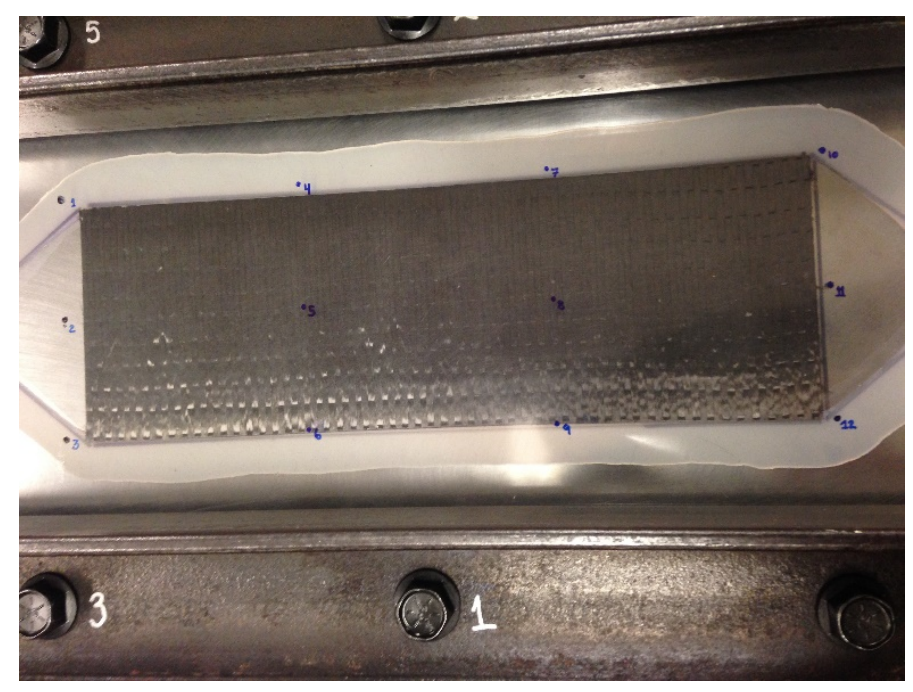

Figure 3-6: Reinforcement Sample in 1-D Flow Tool with Silicone Seal

A sample of $300 \mathrm{~mm} \times 100 \mathrm{~mm}$ area was loaded in the tool, and the tool was clamped shut using 6 Grade 8 bolts torqued to $20 \mathrm{ft}-1 \mathrm{bs}$. Canola oil test fluid was driven through the sample by pressurized air applied to a tank containing the resin pot and inlet tube. Following methods described in Section 2.5, the time required for the oil to reach length increments of 50 mm was recorded for each sample and the permeability calculated by the one-dimensional version of Darcy's Law:

$$
K=\frac{L^{2} \mu\left(1-v_{F}\right)}{2 t \Delta P}
$$

Where $L, t, \mu$, and $\Delta P$ denote the flow front length, time at that length, oil viscosity, and applied fluid pressure gradient, respectively.

\subsubsection{3-Dimensional Comparison Tool}

An additional 3-D permeability measurement tool was used to compare the continuous permeability measurements of the DIC/DAQ. Rigid tooling was used for both the top and 
bottom of the mold. These were made from thick acrylic plates $(300 \times 300$ x $80 \mathrm{~mm})$ and machined with $6 \mathrm{~mm}$ diameter holes in the top plate, for both inlet and vent lines shown in Figure 3-7. The rigid tool's cavity thickness was set by thickness spacers to achieve $51 \% v_{F}$ (JBM) and $62 \% v_{F}(\mathrm{NCF})$. Fabric samples were cut at $150 \times 150 \mathrm{~mm}$ for testing. A pressure pot forced flow into the top center of the sample, and the shape of the flow front was measured at the moment the flow touched the bottom of the cavity. Permeability values were determined using the model described in (George 2014).

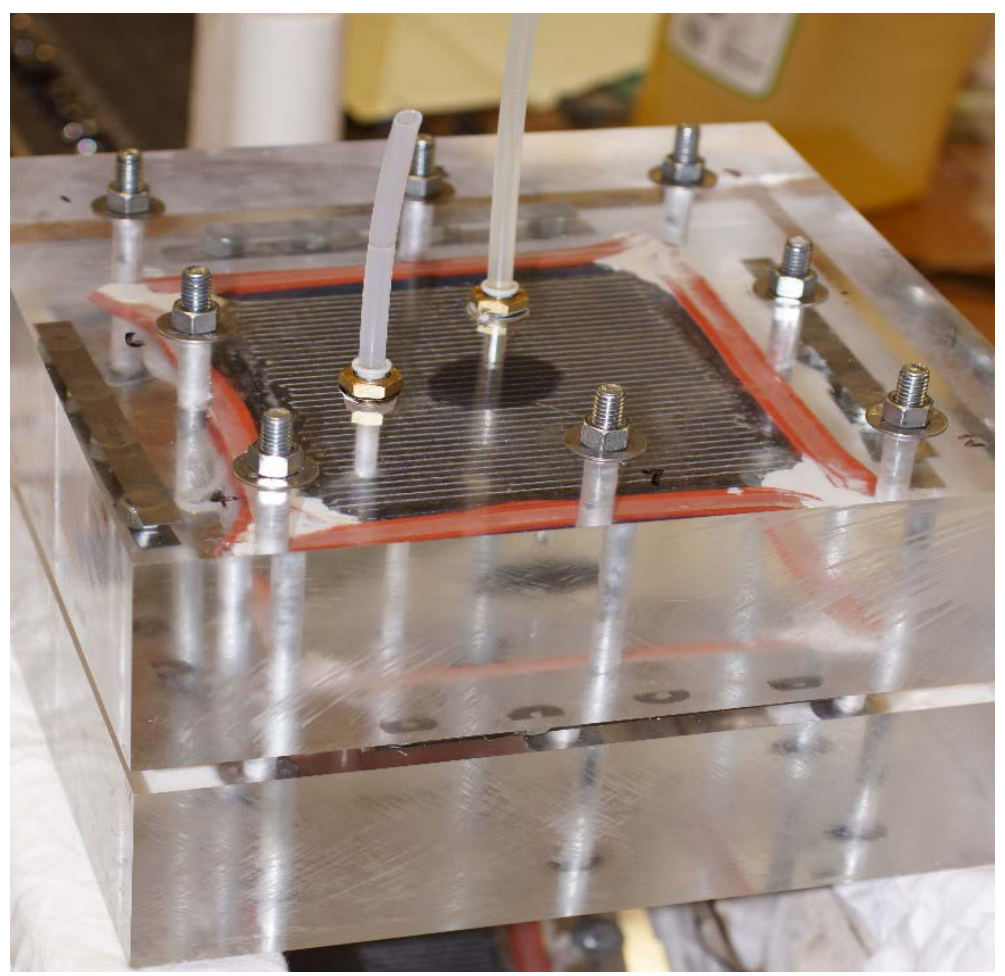

Figure 3-7: 3-Dimensional Comparison Tool 


\subsubsection{Continuous Permeability Tool}

The continuous permeability measurement methodology proposed in this study relies on a vacuum infusion test, with concurrent measurements for 1) the flow front length vs. time, 2) the fluid pressure at various locations in the mold, and 3) the thickness of the sample under the vacuum bag at each of those locations.

Pressure sensors (Dwyer 628-00-GH-P9-E1-S1) were threaded into a steel plate, to be flush with the tool-side surface. These were placed at 20,40,60,80, 100, and $200 \mathrm{~mm}$ along the flow path through the long direction of the fabric sample and were spaced at $50 \mathrm{~mm}$ increments across the test fixture as demonstrated in Figure 3-8. The sum $P_{R}+P_{V}$ (refer to Equation 2-3) was continuously measured at each sensor throughout the duration of each infusion test.

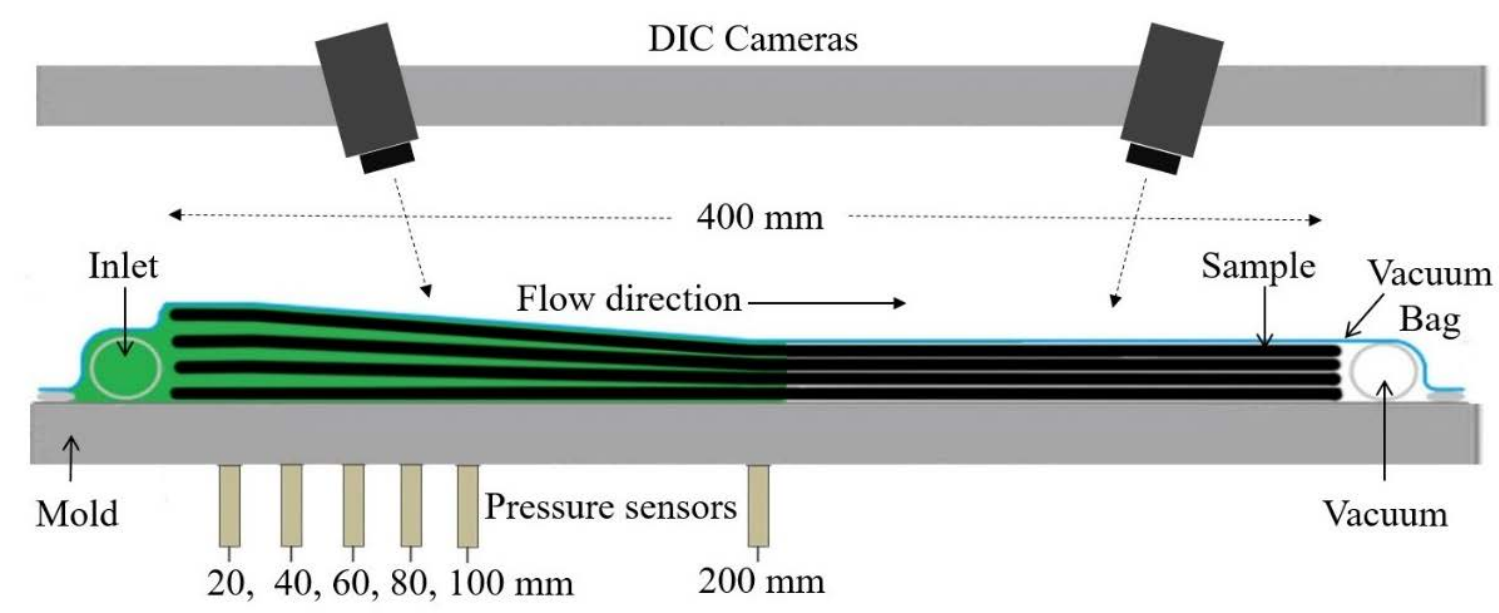

Figure 3-8: VI Test Setup for Continuous Permeability Measurement

An Aramis/GOM digital image correlation (DIC) system was employed to measure and record the vacuum bag height across the bag surface. A speckle pattern was applied to the vacuum bag, so the bag displacement could be measured by the DIC. DIC was chosen for thickness measurement due to its unique ability to continuously measure extension across the 
entire vacuum bag surface, giving the most complete picture of the nonlinear transverse fabric displacement in VI (Anderson 2003). The VI thickness gradient can also be measured with extensometers, but requires care to avoid indentation into the fabric samples through the flexible tooling (Korkiakoski 2016).

\subsection{Fiber Orientation and Sample Layup}

For the continuous measurement method, samples were made of four plies of each fabric, cut to 400 x $250 \mathrm{~mm}$. Four infusions were made in the warp direction ([0] $\left.]_{4}\right)$, and three more in the weft direction $\left([90]_{4}\right)$, for each reinforcement type.

\subsection{Test Procedures}

Each continuous permeability measurement test consisted of the following procedure. A fabric sample was laid on the steel plate tool. A vacuum bag with spiral tubing for inlet and vent was placed over this, and a speckle pattern of paint was applied to the bag. The sample was first compressed at full vacuum for 10 minutes, then infusion was begun from one end of the fabric. Infusions were carried out with an atmospheric pressure of $\sim 86 \mathrm{kPa}$ (mountain elevation) and vacuum pressure of approximately $1 \mathrm{kPa}$ (absolute).

A strip of masking tape was placed on the vacuum bag along the flow direction, close to one side of the sample before painting the bag. This tape was removed after the speckle paint pattern was applied, to leave the fibers visible through the bag and allow flow front observation

during infusion. Figure 3-9 shows the method used to measure the time $(t)$ required for the flow front to reach $20 \mathrm{~mm}$ increments in flow length $(L)$. 


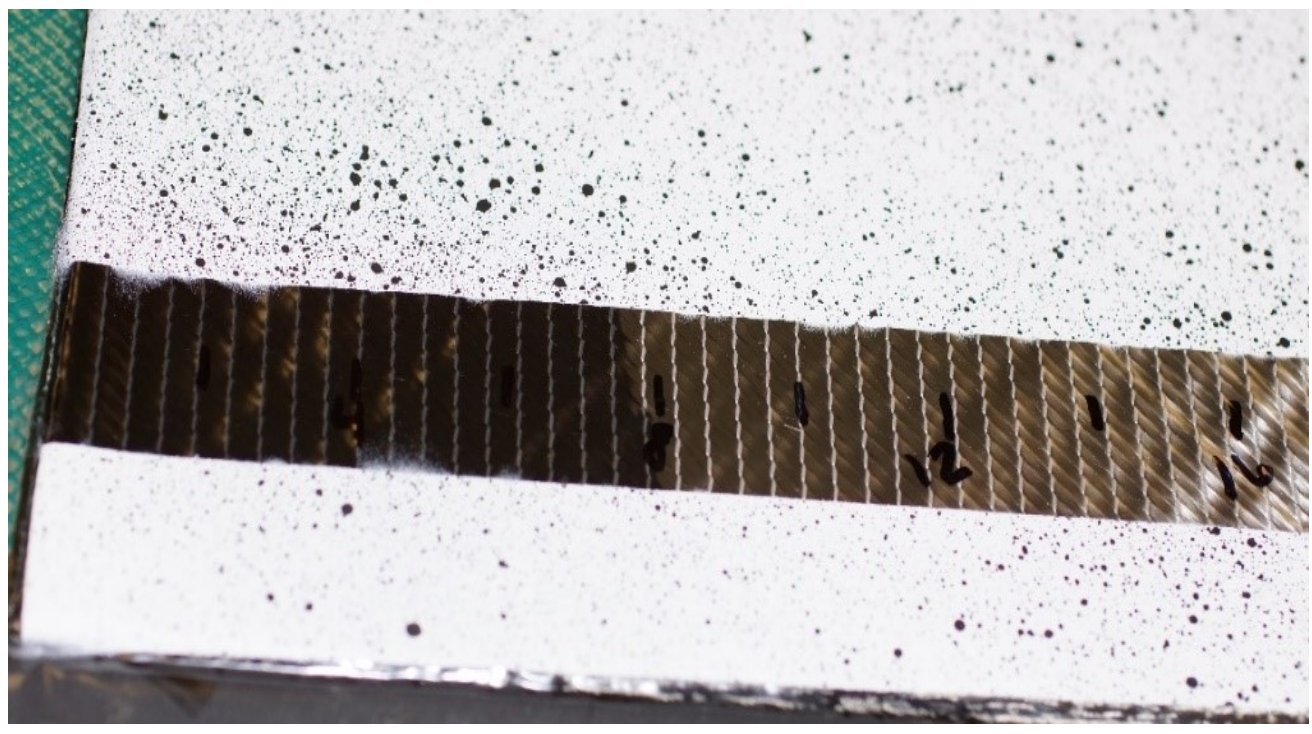

Figure 3-9: Flow Length Measurement through Gap in Speckle Paint Pattern

Both the pressure sensors and the DIC cameras sampled at a frequency of $1 \mathrm{~Hz}$ for the fiberglass materials, or $0.5 \mathrm{~Hz}$ for carbon, throughout the duration of each infusion experiment. The thickness of the sample was measured at the corresponding location of each pressure sensor.

\subsection{Compressibility Measurement and Model}

The resulting data for thickness and $P_{R}+P_{V}$ was converted into $v_{F}$ and $P_{C}$ (Equation 3), and then plotted against each other for each time step. Such compressibility curves $\left(P_{C}\left(v_{F}\right)\right)$, from each of the sensors for a warp-direction infusion for each of the two tested fabrics, are shown in Figure 3-10. Only the wet expansion $P_{C}\left(v_{F}\right)$ data is shown, i.e. from the point at which the flow front reaches the sensor location. The $200 \mathrm{~mm}$ sensor curve is not shown for carbon as the fluid pressure remained low throughout the test duration. 

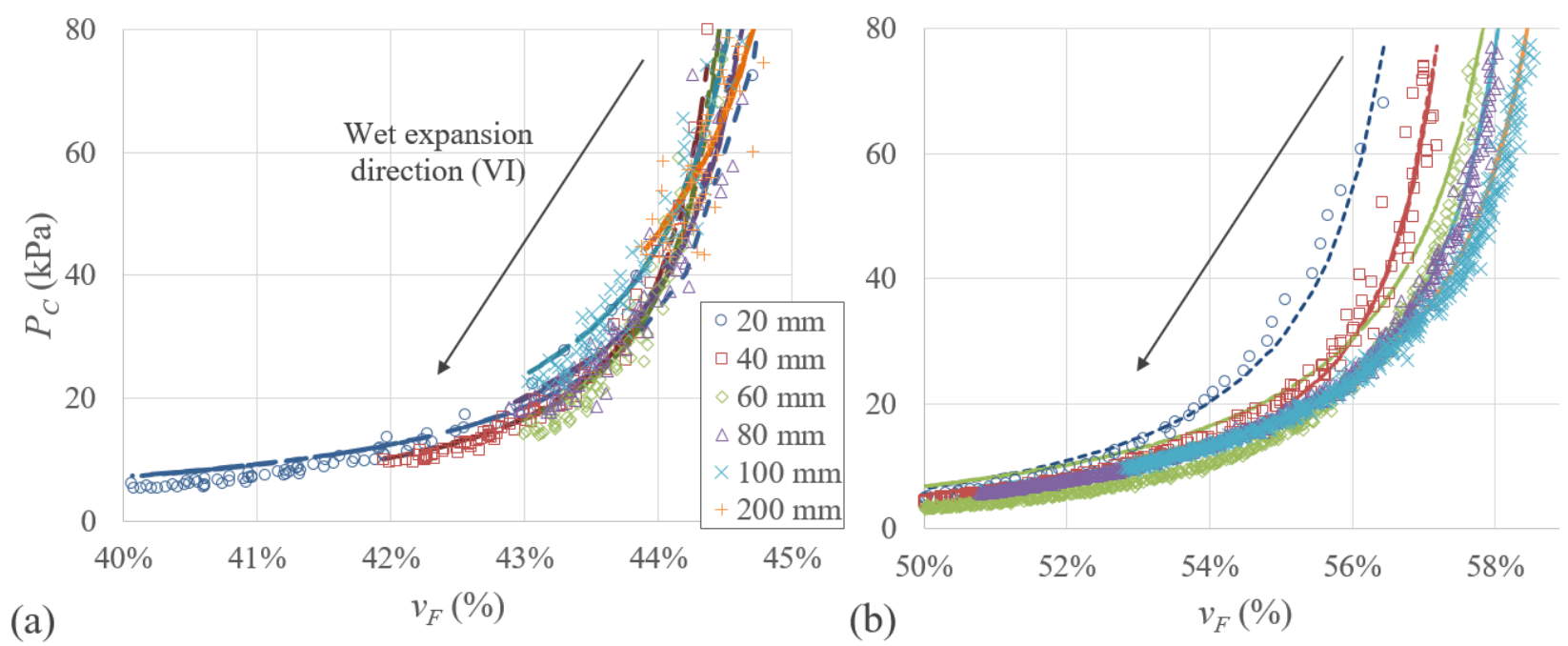

(b)

$v_{F}(\%)$

Figure 3-10: Example Compressibility Curves Determined from Pressure Sensors and DIC during Infusion: (a) Fiberglass UBW and (b) Carbon NCF

Also shown in Figure 3-9 are fitted models to each of the compressibility curves. Both inelastic models (Gutowski 1987, Andersson 2005) and nonlinear elastic empirical models (Gutowski 1987, Song 2003) including a power law (Modi 2008, Robitaille 1999) have been developed to describe the compressibility. In this study, the Song-Loos model (Song 2003) was used:

$$
\varepsilon_{w}=a+b\left(\frac{P_{C}}{c+P_{C}}\right), \varepsilon_{w}=1-\left(\frac{v_{F 0}}{v_{F}}\right)
$$

The variables $\varepsilon_{w}, v_{F 0}$ and $a$ are the wet strain, the initial (minimum) dry $v_{F}$, and the wet strain in the un-compacted state, respectively, and $b$ and $c$ are empirically fitted constants. This model was chosen as it is a fairly simple empirical model to implement in flow simulation and it resulted in agreeable fits of the VI wet expansion data in Figure 3-10. Values for the fitted constants are presented in Table 3-2 for the two materials shown in Figure 3-10. 
Table 3-2: Average Fitted Values for VI Compressibility Measurement

\begin{tabular}{|l|l|c|c|c|c|}
\hline \multicolumn{2}{|c|}{ Reinforcement } & \multirow{2}{*}{$\begin{array}{c}v_{F 0} \\
(\%)\end{array}$} & $a$ & $b$ & $c(\mathrm{~Pa})$ \\
\hline \multirow{2}{*}{ Glass UBW } & warp & \multirow{2}{*}{30.1} & -0.430 & 0.762 & 869 \\
\cline { 2 - 4 } & weft & & -0.289 & 0.626 & 1,440 \\
\hline \multirow{2}{*}{ Carbon NCF } & warp & \multirow{2}{*}{34.9} & 0.226 & 0.190 & 7,690 \\
\cline { 2 - 4 } \cline { 5 - 6 } & weft & & 0.127 & 0.289 & 5,516 \\
\hline
\end{tabular}

As this is wet expansion, the data starts at the top-right highest $v_{F}$ and proceeds down and to the left along the curve through the experiment's duration. The closest sensor (at $20 \mathrm{~mm}$ ) starts at slightly lower $v_{F}$ for the carbon NCF because it had less dwell time under load before infusion, to experience creep deformation through fiber rearrangement (Robitaille 1999). The closest sensor also had the fastest expansion, thus a slightly stiffer (steeper) curve, compensating for the lower $v_{F}$ and ending up at a similar uncompressed $v_{F}$ to the other sensor locations. The difference between initial $v_{F}$ and stiffness decreases as the subsequent sensor locations are evaluated at $20 \mathrm{~mm}$ increments farther down the mold.

The compressibility will be slightly different between samples of the same reinforcement, because:

1. The "dwell" time while compressed and relaxed (in between turning pump on/off before infusion) is different for each. Composite reinforcements demonstrate pressure decay/creep deformation while held under load: the fibers slowly rearrange for better nesting; with the constant load of atmospheric minus vacuum pressure on the fibers, they slowly compress to higher $v_{F}$ values, which makes the fabric stiffer (more dense) (Robitaille 1999). The farther the sensor location, the longer time it has a dry compression before being infused and expanded. So, farther sensors from the inlet have slightly higher $v_{F}$ than sensors close to the inlet. 
2. Rate-dependency: the flow rate is a little different from sample to sample due to permeability variation/race-tracking. Different flow rate means a different expansion rate on the fabric during infusion (faster flow $=$ fast expansion). It is also different from sensor to sensor as the flow rate slows down as the flow gets farther from the inlet. A wet composite is viscoelastic, meaning the compressibility is dependent on the rate of displacement. A faster expansion rate means it will stay at higher $v_{F}$ values for longer (steeper compressibility curve).

3. Pre-compression/handling: draping characterization, the fabric is sheared and compressed on the roll, and cutting/preparing samples - and this is different for each sample.

\subsection{Data Collection Procedures}

There were several lessons learned from early experimental work, which allowed later optimization of the methodology. The DAQ data always exhibited a little noise, but the DIC data was often very noisy in early infusion experiments. Suspected causes of the experimental noise were:

1. (Affecting only DIC) Slight vibration of DIC cameras (or mold/table)

2. (Affecting only DIC) Possibly lighting variation on speckle pattern from the ceiling lamps, passing operators, etc.

3. (Affecting both DAQ and DIC) Change in elevation of the top level of oil in the pot from handling the tube/pot, and the slow draining of the pot during infusion, the top oil level would change in height, which made significant changes to the hydrostatic head pressure applied on the inlet.

In later experiments, the DIC camera system was mounted more securely, on a bar elevated at both ends instead of a single tripod. A fluorescent lamp was suspended from the bar 
directly over the speckle paint, to give a bright and constant light source. A wide (200 mm) oil reservoir was used as the pot and positioned so that the liquid level was flush with the top surface of the mold at the beginning of the test shown in Figure 3-11. Over the course of infusing a reinforcement sample, the liquid height dropped by about $7 \mathrm{~mm}$ in each test. The decrease in hydrostatic pressure over this height given the oil's density is less than $0.1 \mathrm{kPa}$, which was deemed insignificant. Thus, the inlet $P_{R}$ was assumed constant.

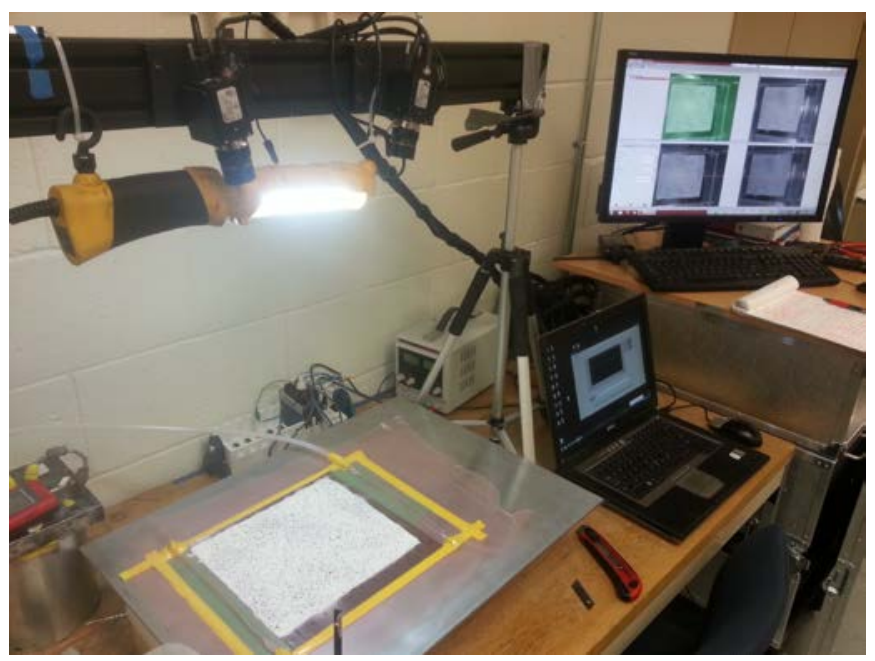

Figure 3-11: New VI Infusion to Minimize "Noise"

\subsubsection{DAQ and DIC Calibration:}

Compressibility testing requires high precision in measurement of the thicknesses of the sample. For the four ply samples used in this study, a change in the initial thickness measurement of only $0.1 \mathrm{~mm}$ in the JB Martin fiberglass and NCF carbon results in a change of $3 \%$ in $v_{F}$ for both fabrics shown in Figure 3-12. This same change in initial thickness value results in a difference as great as $19 \%(\mathrm{JBM})$ and $16 \%(\mathrm{NCF})$ in permeability at the low end of the fiber volume ranges, which is also displayed in Figure 3-12. To put in perspective how 
significant this small span can be, the first compression to $86 \mathrm{kPa}$ of the same material requires $0.5 \mathrm{~mm}$ displacement, but the subsequent relaxation only requires $0.15 \mathrm{~mm}$. Further complicating the issue, dry reinforcements are not as stiff as metals, thus this degree of precision is difficult to obtain. Using higher ply counts reduces the potential error associated with thickness measurement, but also consumes extra fabric. Incidentally, if more plies are used than in the intended manufacturing application, higher nesting (more ply-to-ply interfaces) results in a higher $v_{F}$, and vice-versa. Four plies were used in all test cases in this proof-of-concept study as an extreme in precision difficulty (and to conserve fabric); any higher ply count should be an easier case.
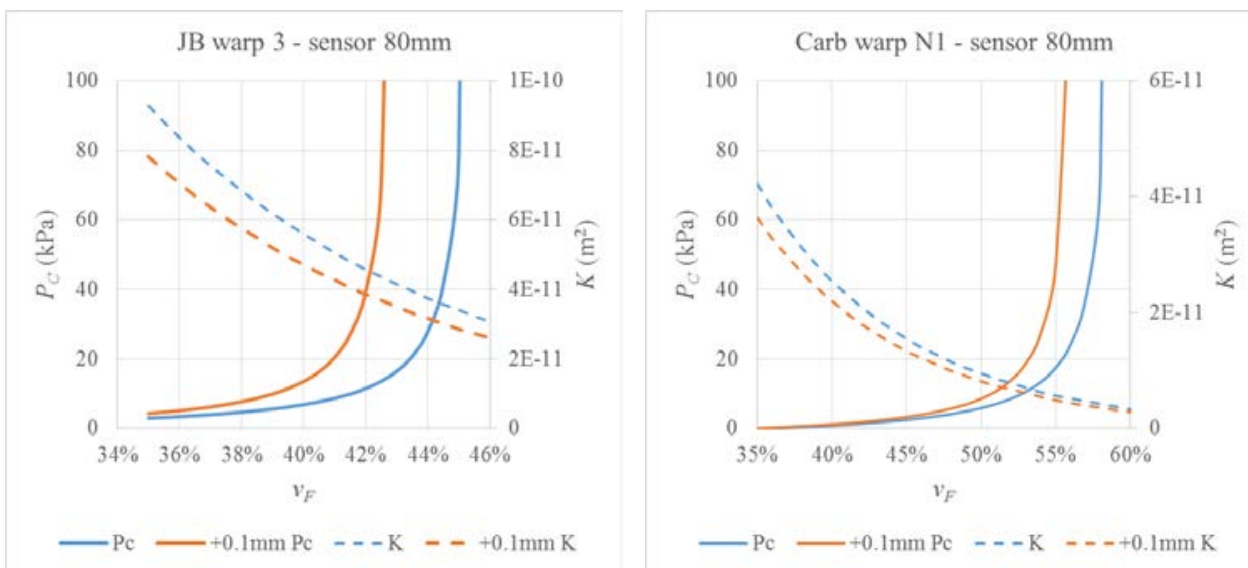

Figure 3-12: Sensitivity of Compressibility $\left(P_{C}\right)$ and Permeability $(K)$ to Initial Thickness Measurement for UBW (left) and NCF (right) in the Warp Direction

Thickness calibration of the DIC displacement data was performed by vacuum bagging dry samples of the test fabrics with breather cloth overlapping the edges of the fabric samples and the vacuum source tube. After 10 minutes of vacuum compression, a long-arm digital caliper (Mitutoyo Model \#209-534) was used to measure the thickness of the fabric sample, using a strip of $0.5 \mathrm{~mm}$ precision thickness gauge to minimize indentation of the spring-loaded 
caliper ends into the fabric sample. This measurement was repeated in at least three separate locations $50 \mathrm{~mm}$ apart from each other for each fabric sample and the average of all the measurements used for calibration. The difference between measurements across either sample was approximately $0.01 \mathrm{~mm}$. A start thickness for the DIC displacement data was then assumed which aligned the thickness at the end of the same 10-minute dwell during each VI test with that measured in this calibration experiment. 


\section{RESEARCH RESULTS AND ANALYSIS}

The continuous permeability test results in values for atmospheric pressure $\left(P_{A}\right)$, vacuum pressure $\left(P_{V}\right)$, and resin pressure $\left(P_{R}\right)$. The latter is measured using the pressure sensors. The compression pressure $\left(P_{C}\right)$ is determined using Terzaghi's equation (Equation 2-3) from the other pressure measurements. The Song-Loos equation is used to fit the compressibility model $\left(P_{C}\left(v_{F}\right)\right)$ to the experimental compression pressure and thickness data (as measured with DIC). The values for $a, b$, and $c$ in the Song-Loos model are fit to this data. A MatLab optimization script (Appendix B) of Equation 2-5 is then used to fit the predicted flow front $(L, t)$ with the measured data captured with the infusion experiment by iterating the value of the KozenyCarman constant $(k)$. A visual representation of the iterative process is shown in Figure 4.1. The optimized Kozeny-Carman constant is used in the Kozeny-Carman Equation to determine permeability $(K)$.

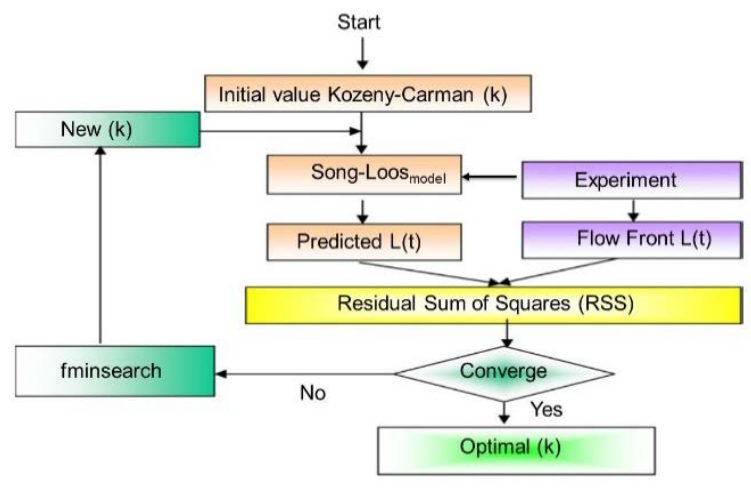

Figure 4-1: MatLab Process for Optimization of Kozeny-Carman Constant ( $k$ ) 


\subsection{Choice of Permeability Model}

The usual assumption in flow simulation is to model the permeability as a function of only the fiber volume content (Gebart 1996). As mentioned in Chapter 2, two common models exist in the literature for modelling $K\left(v_{F}\right)$ : a power law (Equation 2-1), and various forms of the Kozeny-Carman equation (Equation 2-2). The simplest version arises from lumping all the constants into one, the Kozeny constant, $k$, as seen in Equation 2-2.

Since Equation 2-2 is more commonly used, and has only one constant to fit instead of the two constants in a power law, that is the model that was chosen in this study. To run the filling model of Equation 2-5, the derivatives of $h$ and $K$ must be evaluated symbolically with respect to the fluid pressure $P_{R}$. As $h \cdot v_{F}$ is a constant (areal weight divided by fiber density), Equation 3-8 yields:

$$
\frac{\mathrm{d} h}{\mathrm{~d} P_{R}}=\frac{h b c v_{F}}{v_{F 0}\left(c+P_{A}-P_{R}\right)^{2}}
$$

Combining Eq. 9 and the Kozeny-Carman model (Equation 2-2):

$$
\frac{\mathrm{d} K}{\mathrm{~d} P_{R}}=\frac{\mathrm{d} h}{\mathrm{~d} P_{R}} \frac{k}{h} \frac{\left(1-v_{F}\right)^{2}}{v_{F}{ }^{2}}\left[3 v_{F}+2\left(1-v_{F}\right)\right]
$$

Fitting the Kozeny-Carman equation (Equation 2-2) results in a $K\left(v_{F}\right)$ plot with curvature matching that of one-dimensional testing, and is an accurate reflection of observed measurements. Optimization of Equation 5 using the Kozeny-Carman equation showed a clear single minimum across a wide range of guess values displayed in Figure 4-2. The KozenyCarman Equation was thus deemed adequate for inverse estimation fitting of the permeability given experimental flow length data and the results below employ that model. 


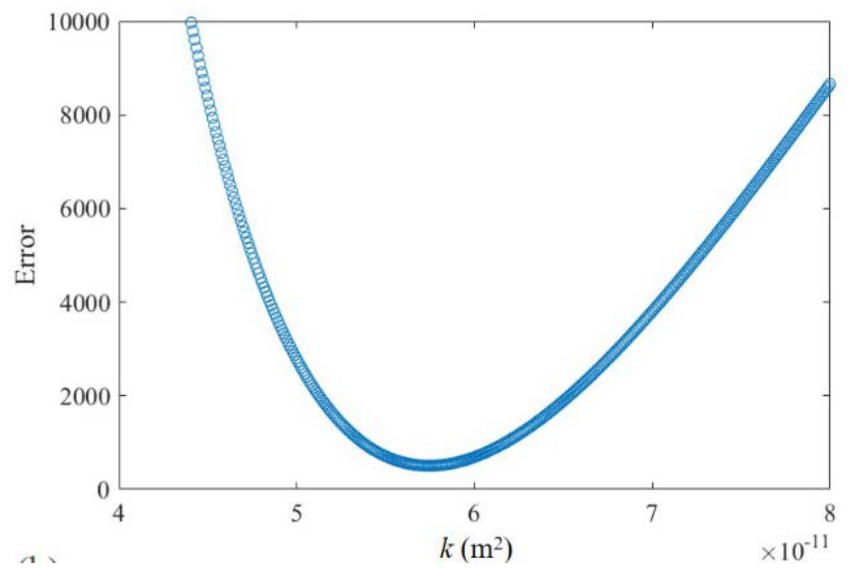

Figure 4-2: Surface Plot of Residual Error in Permeability Fitting

\subsection{Compressibility Fits}

Referring back to Figure 3-10, the compressibility curves for the glass reinforcement are fairly similar, while more variety is seen in the carbon reinforcement. The closest sensor to the inlet (at $20 \mathrm{~mm}$ ) for the carbon example infusion starts at slightly lower $v_{F}$ as seen in the top right corner of Figure 3-10(b). This suggests that a significant amount of dry compaction continues in the dry region after the infusion begins, effectively extending the compaction dwell beyond the original 10 min duration. Such a difference in compressibility for varying dwell durations has been previously reported (Robitaille 1999). The closest sensor at $20 \mathrm{~mm}$ in Figure 3-10(b) also had the highest rate of expansion. The slightly stiffer (steeper) compressibility curve can be attributed to the higher rate (Comas-Cardona 2007). The differences in initial $v_{F}$ and stiffness between adjacent sensor locations decreases farther from the inlet.

Figure 4-3 illustrates the sensitivity in $K\left(v_{F}\right)$ to the choice of compressibility model for the carbon reinforcement. The "baseline" curve represents the permeability fit for one warp direction experiment's $L(t)$ data when using the average compressibility curve from all warp tests. The other compressibility models come from the sensor locations where the 
compressibility was the most different from the average model. For example, the stiffest compressibility observed in all carbon warp direction testing was shown in Figure 3-10(b) (20 mm location). This and the most compliant compressibility curve seen in all sensor data from the warp-direction infusions were each input into the permeability fitting model for the same set of $L(t)$ data. This was then repeated for the stiffest and most compliant compressibility curves from the weft-direction infusions. The largest deviation from the "baseline" is $23.8 \%$ in the predicted permeability. Given this, and the relative difficulty to account for the change in compressibility at the flow front as it moves past each sensor, using the average compressibility of all sensor measurements was assumed to be a suitable approximation.

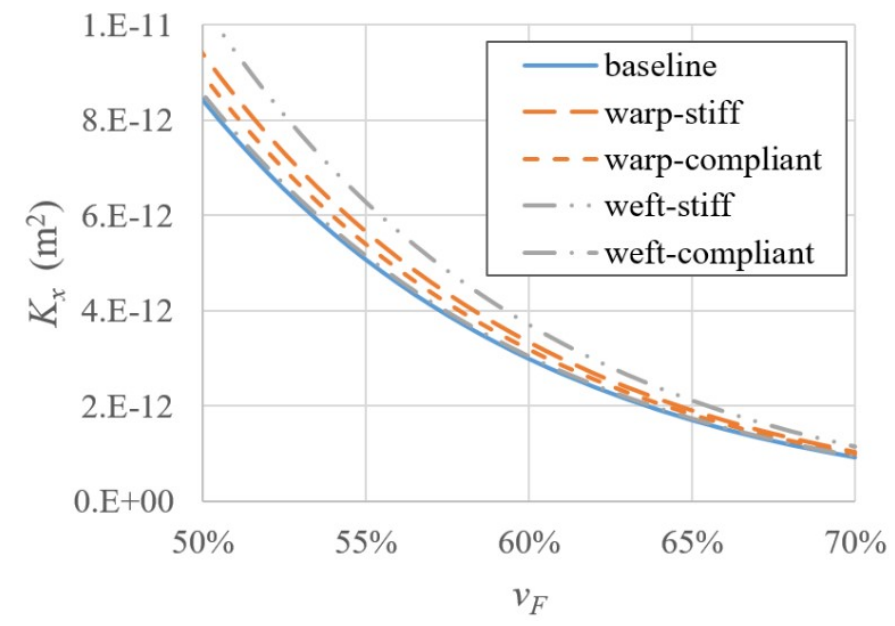

Figure 4-3: $K$ Fit Sensitivity to Compressibility Model

The average compressibility as calculated for both the warp and weft directions for each material is illustrated in Figure 4-4. The model fits (Equation 8) for these average compressibility curves were listed in Table 3-1. For the carbon NCF, there is a small difference between the warp and weft direction infusions in the low- and high-pressure extremities of the compressibility curves; $4 \% v_{F}$ at the low end and $2 \%$ at the high end. The stiffer response of the 
warp-infusions in the high-pressure region of the curve is thought to again be due to expansion rate differences; as the flow rate is faster in warp than weft, so is the expansion rate. As in Figure 4-3, these differences were deemed small, thus the warp compressibility was used for all permeability fits, including for experiments with weft-direction flow.

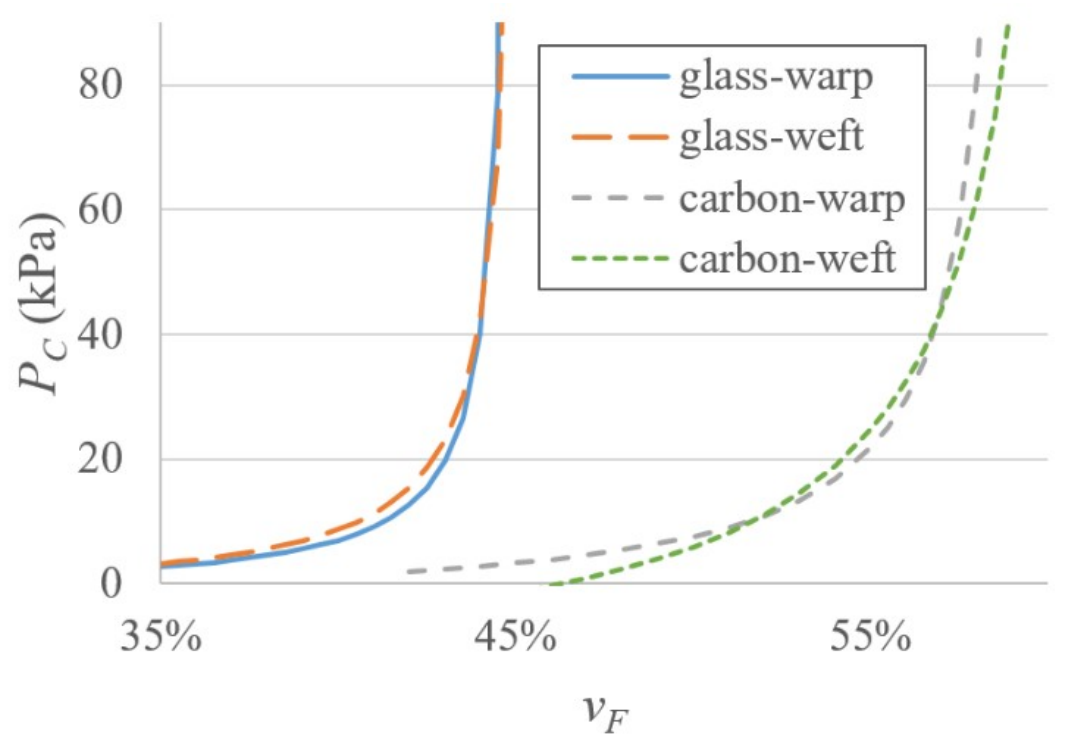

Figure 4-4: Comparison of Average Compressibility Models from Warp and Weft

\subsection{Permeability Fits}

Figure 4-5 presents the Matlab-produced plots of the experimental flow front data (blue lines) and the predicted flow front data by Equation 5, with the optimized value of $k$ for the permeability model. This exponential shape of the $L$ vs. $t$ profile is common to Darcy flow, and is well matched by the simulation program. 

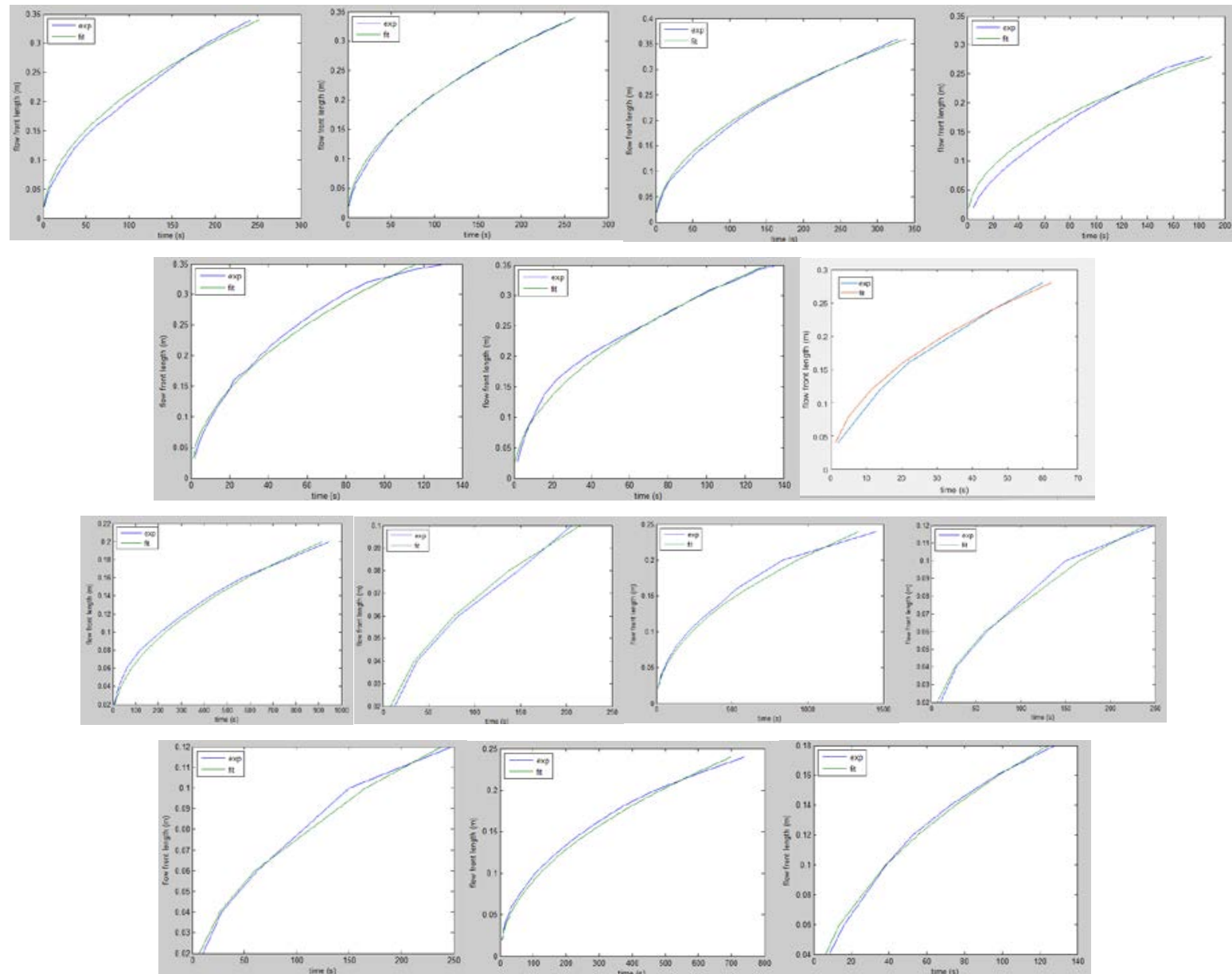

Figure 4-5: Goodness of Fit Comparison for each Infusion Experiment, Arranged by Rows; from Top to Bottom-- Glass UBW Warp, Weft, Carbon NCF Warp, Weft

Figure 4-6 shows the $L^{2}(t)$ plots for all infusions, as well as the predicted times from the permeability fits by the Kozeny-Carman model (Equation 2-2). In unidirectional flow through a rigid mold, e.g. resin transfer molding (RTM), such a plot should be linear as predicted by integration of Darcy's law. The empirical data and model fits shown in Figure 4-6 exhibit only slight non-linearity due to the thickness gradient inherent in VI. The fit of the predicted times to the empirically measured $t$ data was a good match. Good agreement was observed for the data when grouped by warp and weft direction for the glass materials, while difference is seen in directionality for the carbon infusions. The data for the glass weft 3 and carbon warp 3 tests 
exhibits a shorter test length than the other tests due to significant flow race-tracking occurring beyond the flow lengths shown.
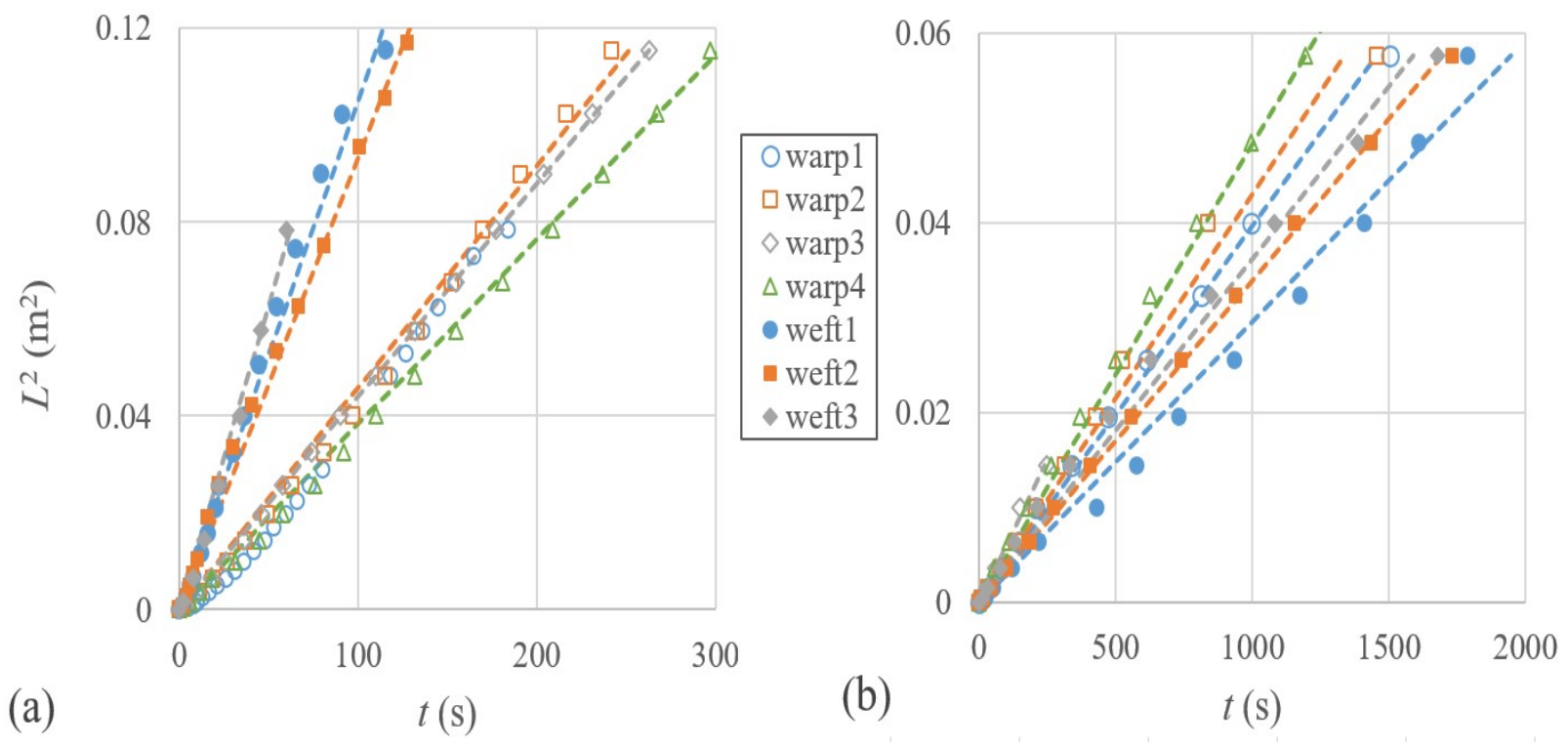

Figure 4-6: $L^{2}(t)$ Measurement (Symbols) and Fit (Dashed Lines) for (a) UBW and (b) NCF Reinforcements

Plots of $K\left(v_{F}\right)$ were prepared from the fitted permeability (Equation 2-2) for each infusion, and the results are shown in Figure 4-7. Again, the warp and weft directions show a clear difference in the glass reinforcement, with $K_{y}$ being approximately three times higher than $K_{x}$. Better agreement is seen between the separate infusions for warp compared to weft directional flow. The same can be said about the carbon infusions, although any difference between $K_{x}$ and $K_{y}$ is less clear. 


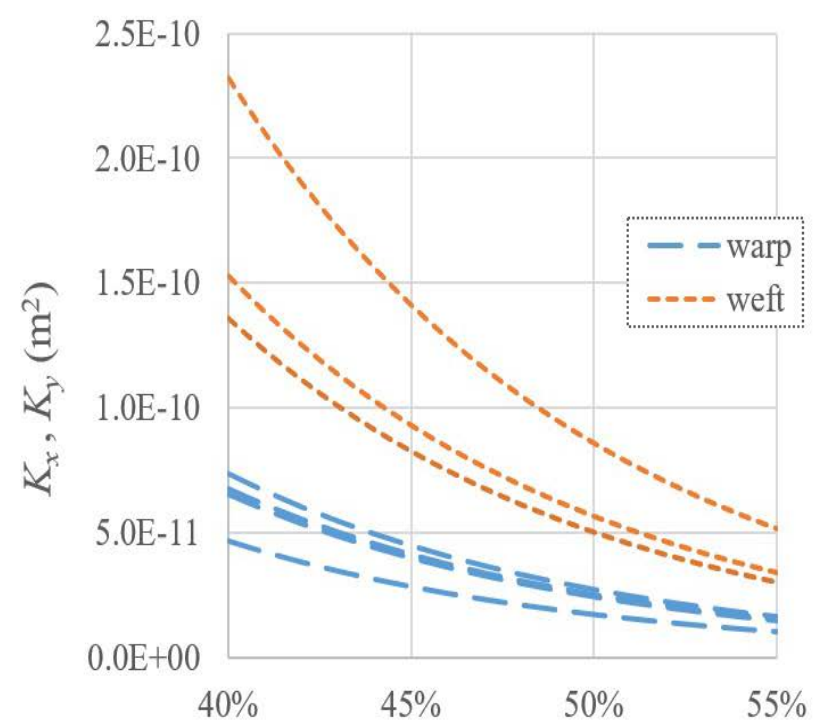

(a)

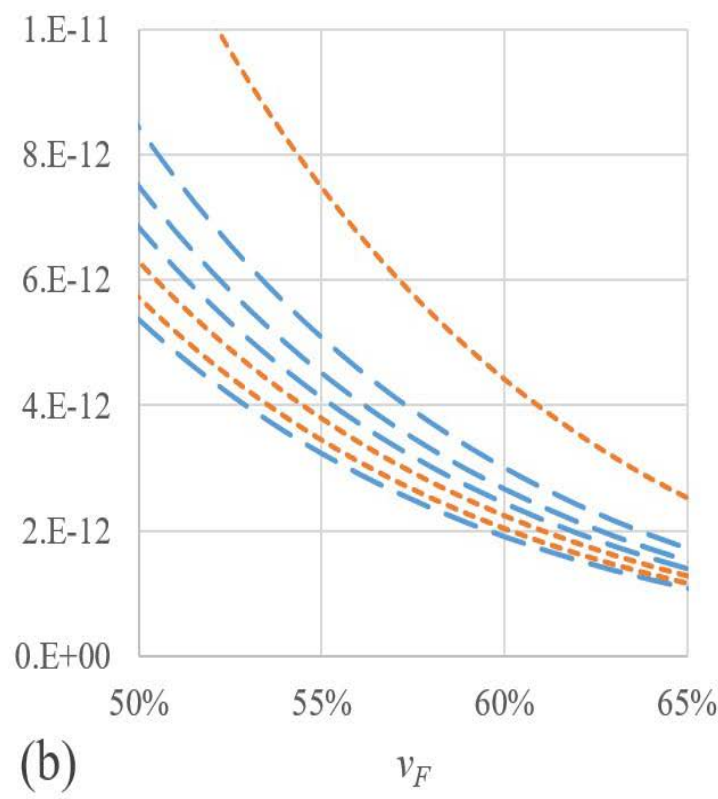

(b)

Figure 4-7: $K\left(v_{F}\right)$ Plots for All Infusions: (a) Glass UBW and (b) Carbon NCF

The average permeability plot of $K\left(v_{F}\right)$ for all infusions from each direction and reinforcement was calculated and is presented in Figure 4-8. The standard deviation, $\sigma$, represents the scatter between the separate infusions, and is presented as upper and lower bounds around that average. The standard deviation for the glass warp and weft infusions was $18.1 \%$ and $29.7 \%$ respectively. For carbon, $\sigma$ was $12.8 \%$ for warp and $29.2 \%$ for weft. This scatter is deemed an acceptable measure of repeatability as $\sigma$ compares favorably with the usual scatter in 1-D permeability measurement (Vernet 2014). The average fitted Kozeny constant $k$, in the warp and weft directions respectively, was 8.44 and 12.8 for glass, and 1.46 and 1.39 for carbon (all in $\left.10^{-11} \mathrm{~m}^{2}\right)$. 

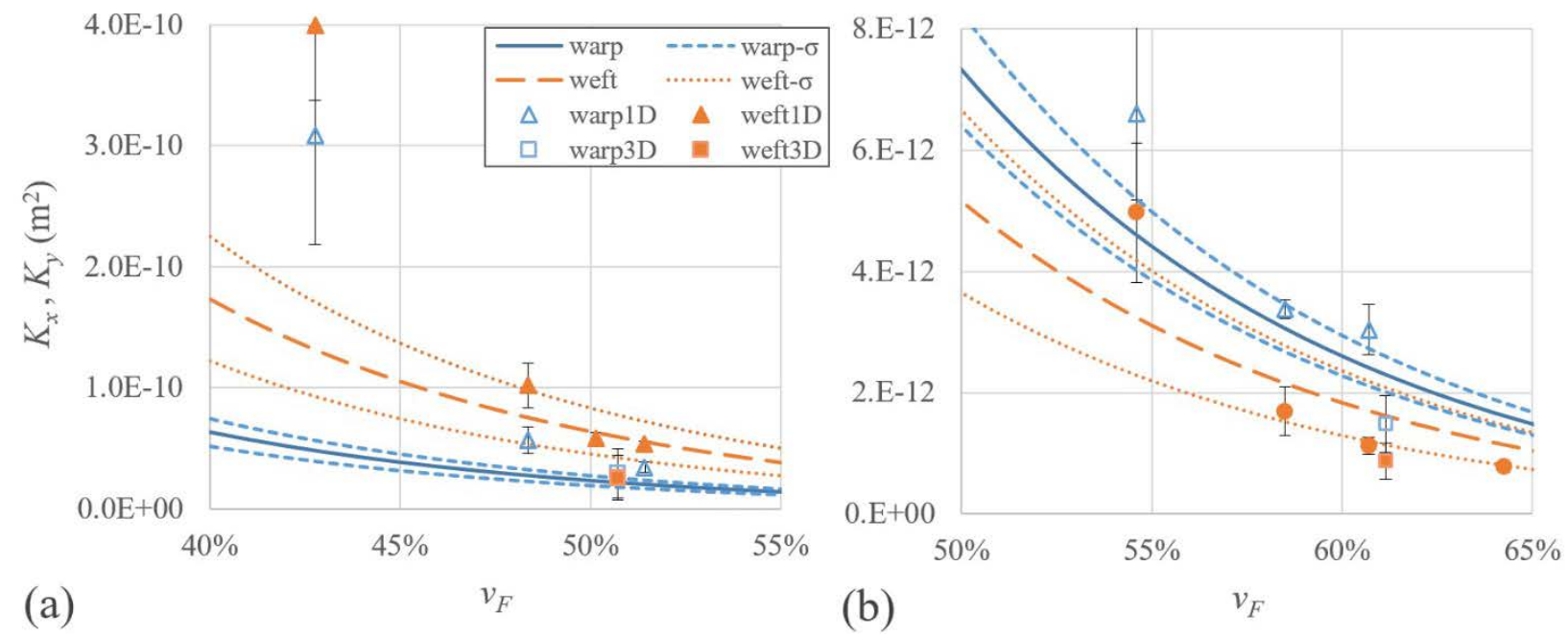

Figure 4-8: Average Fit of $K\left(v_{F}\right)$ for (a) Glass UBW and (b) Carbon NCF, with Standard Deviation $(\sigma)$ Upper and Lower Bounds; Compared to 1D and 3D Permeability Test Results

Included in Figure 4-8 are comparative data from independent testing using two other non-continuous permeability measurement methods. The first method is based on unidirectional wetting flow in a rigid cavity in Section 3.2.1, similar to the methodology outlined in the recent worldwide benchmark (Vernet 2014), repeated at three to four different thicknesses. The second method is based on three-dimensional ellipsoidal wetting flow in a rigid mold described in Section 3.2.2. A minimum of three repeat experiments were performed for each permeability data point. The low $v_{F}$ results from unidirectional flow testing for the glass JBM were three (weft) to eight (warp) times the permeability as measured by the VI method.

Similar results were observed in a recent worldwide permeability benchmark study (Arbter 2011), where a carbon twill weave fabric was used. Permeability tests were conducted by several different laboratories on the same fabric, using a variety of test methods, including the unidirectional wetting flow used as a comparative measurement method in this study. The standard deviations across permeability results from the benchmark study were generally smaller at higher fiber volume fractions. The gradient of the $K\left(v_{F}\right)$ curve in that study, shown in Figure 
4-9 (Arbter 2011), is similar to that seen in the VI curves in Figure 4-8 above, where a 10\% increase in $v_{F}$ results in roughly a $50 \%$ decrease in the permeability. In contrast, the unidirectional flow test results in this study showed a far greater gradient at low values of $v_{F}$; a $75 \%$ decrease in permeability is seen in the fiberglass weft results when decreasing $5 \%$, from $43 \%$ to $48 \%$, in $v_{F}$. These results suggest that the unidirectional test results at low $v_{F}$ may not be as trustworthy as the continuous permeability measurement method, as something is causing them to be overly steep. Although the fabric in the benchmark tests is different from those used in this study, it serves as a general expectation of the observed results, which are consistent with the continuous VI results in Figure 4-8.

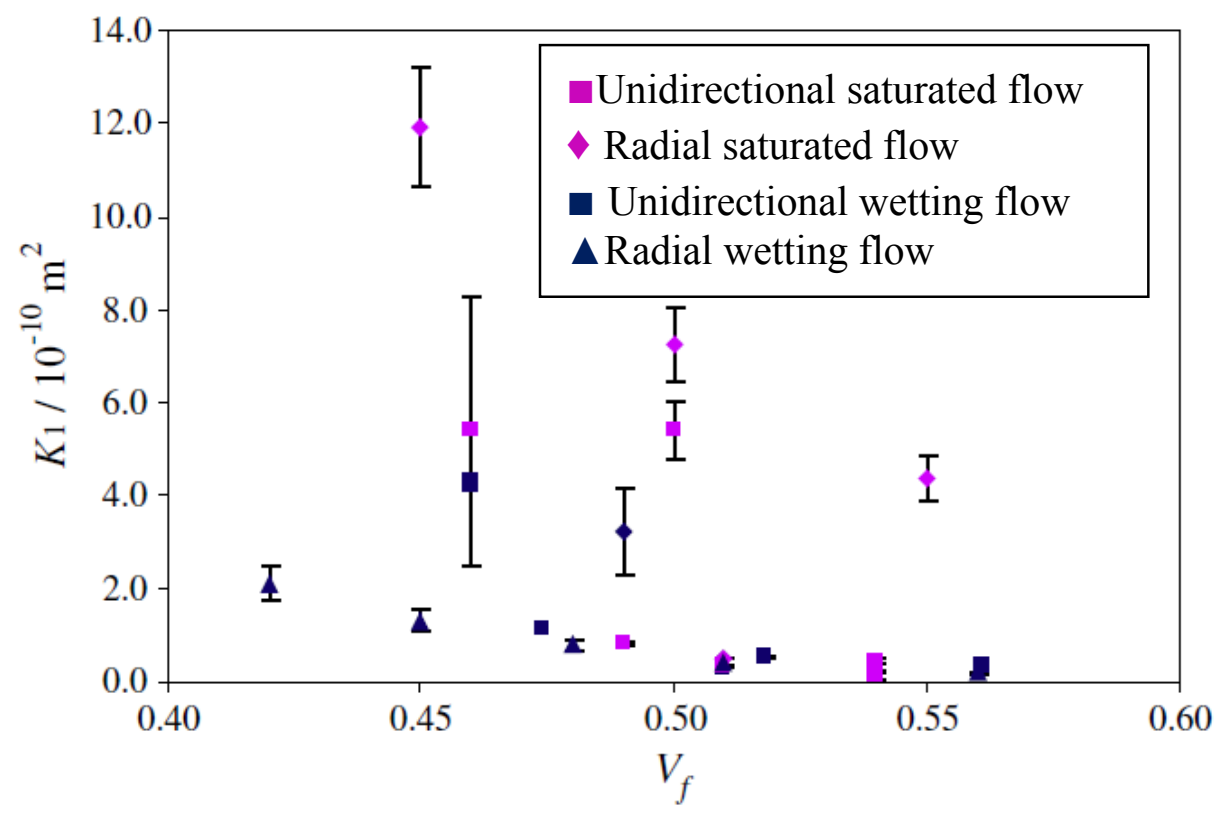

Figure 4-9: Permeability Data Results from Benchmark Study

The cause for this difference is thought to be due to the difference between the rigid cover in the unidirectional test, and the flexible vacuum bag in the VI test. The latter may experience bag nesting between the glass yarns as the glass JBM is a relatively open fabric 
architecture, whereas the rigid top in unidirectional testing may promote open channels between the yarns thus facilitating porosity and capillary flow. This suggests that the permeability test should be matched to the process method to be simulated (i.e. vacuum infusion test for vacuum infusion process) as differences in permeability may result from the flexibility of the tooling. If the low $v_{F}$ glass results are disregarded, the maximum deviation between these independent permeability measurement methods and those presented in this study is approximately $50 \%$. This agreement is as good, or better, than the agreement seen in similar comparisons for the other continuous permeability measurement studies mentioned in Section 2.5 .

\subsection{Sensitivity of Flow Simulation to Permeability}

In Darcy's Law, since permeability $(K)$ is in the numerator, the filling velocity in flow simulation is directly proportional to permeability (Equation 2-6). So, a change in calculated $K$ of $50 \%$ changes the simulated fill time by $50 \%$. If the permeability is constant across a part in fill simulation, a change in $K$ won't change the flow front shape, it will just change the fill time. Thus inlet, feedlines, and vent locations aren't affected in that case. But, if the permeability changes from one location to another (e.g. different compaction levels due to geometry or different number of material plies), then the fill pattern and gate optimization are affected.

As a further note, filling velocity has been directly related to bubble formation during infusion, which is the primary cause of void content (Patel 1995). So, a 50\% change in permeability will significantly affect the type and amount of voids that are formed. Both of these points further reinforce the importance of having accurate permeability measurements across the full range of fiber volume contents. 


\section{CONCLUSIONS}

A novel method is presented here for the rapid measurement of permeability over a continuous range of fiber volume content, in a single unidirectional vacuum infusion flow experiment. The thickness gradient across the vacuum bag as well as the fluid pressure at several locations in the mold were concurrently measured, to calculate the fabric compressibility. An analytical flow model which accounts for the compressibility is then used, by iterating the fitting constant in the Kozeny-Carman model for permeability, until the predicted flow front progression matches empirical measurement for each infusion. Attempts at doing the same with a power law model for the permeability resulted in periodic local minima complicating the fitting procedure, and was deemed inadequate for this optimization method.

Multiple experimental infusions were performed for two reinforcement materials, in both the warp and weft flow directions. The standard deviation across the multiple experiments for each material and orientation ranged from $12.8 \%$ to $29.7 \%$. Validation of these results was performed by comparing the resulting permeability with independent non-continuous permeability measurement tests, of both one- and three-dimensional wetting flow. Low $v_{F}$ glass tests showed significantly faster flow in unidirectional testing than the VI method in this study, suggesting that tooling rigidity may affect the flow on the top of the sample. The maximum deviation between the different test methods for all other samples is approximately $50 \%$. The low standard deviation between experiments and the agreement between methods are good in 
comparison with other continuous permeability measurement methods. The resulting permeability curves $K\left(v_{F}\right)$ are also consistent in shape with that seen in a previous benchmark study, considering differences in the fabrics tested. 


\section{REFERENCES}

Adams, K.L, B. Miller, and L. Rebenfield. "Forced In-Plane Flow of an Epoxy Resin in Fibrous Networks." Polymer Engineering and Science 26(20), 1986: 1434-41.

Alms, J.B., L. Garnier, J.L. Glancey, and S.G. Advani. "In-Plane Permeability Characterization of the Vacuum Infusion Processes with Fiber Relaxation." International Journal of Material Forming, 2010: 1267-75.

Anderson, H.M., T.S. Lundsröm, B.R. Gebart, and P. Synnergren. "Application of Digital Speckle Photography to Measure Thickness Variations in the Vacuum Infusion Process." Polymer Composites, 2003: 448-55.

Andersson, H.M., T.S. Lundström, and N. Langhans. "Computational Fluid Dynamics Applied to the Vacuum Infusion Process." Polymer Composites, 2005: 231-9.

Arbter, R. et. al. "Experimental Determination of the Permeability of Textiles: A Benchmark Exercise." Composites Part A: Applied Science and Manufacturing, 2011: 1157-1168.

Berenberg, B. "Liquid Composite Molding Achieves Aerospace Quality." Composites World. November 01, 2003. http://www.compositesworld.com/articles/liquid-compositemolding-achieves-aerospace-quality.

Buntain, M.J., and S. Bickerton. "Compression Flow Permeability Measurement: A Continuous Technique." Composites Part A, 2003: 445-457.

Carman, P.C. "Fluid Flow Through Granular Beds." Chemical Engineering Research and Desgin 75(1), 1997.

Comas-Cardona, S., C. Binetruy, and P. Krawczak. "Unidirectional Compression of Fibre Reinforcements. Part 2: A Continuous Permeability Tensor Measurement." Composites Science and Technology, 2007: 638-45.

CompositesOne. "Knowledge Center: Closed Molding Presented by Composites One." Composites World. n.d. http://www.compositesworld.com/knowledgecenter/closedmolding/Closed-Mold-Process.

Correia, N. Analysis of the Vacuum Infusion Moulding Process. Dissertation, Nottingham: University of Nottingham, 2004. 
Correia, N.C., F. Robitaille, A.C. Long, C.D Rudd, P. Šimáček, and S.G. Advani. "Analysis of the Vacuum Infusion Moulding Process: I. Analytica Formulation." Composites Part A: Applied Science and Manufacturing, 2005: 1645-56.

Devillard, M., K.T. Hsiao, A. Gokce, and S.G. Advani. "On-Line Characterization of Bulk Permeability and Race-Tracking During the Filling Stage in Resin Transfer Molding Process." Journal of Composite Materials 37, 2003: 1525-41.

Di Fratta, C., F. Klunker, F. Trochu, and P. Ermanni. "Characterizaton of Textile Permeability as a Funciton of Fiber Volume Content With a Single Unidirectional Injection Experiment." Composite Part A: Applied Science and Manufacturing, 2015: 238-47.

Gardiner, G. "Wet Compression Molding." Composites World. January 2, 2016. http://www.compositesworld.com/blog/post/wet-compression-molding.

Gates, D. "At Boeing's 777X Wing Factory, Robots Get Big Jobs." The Seattle Times. November 26, 2016. http://www.seattletimes.com/business/boeing-aerospace/at-boeings-777x-wingfactory-robots-get-big-jobs/.

Gebart, B.R., P. Lidström. "Measurement of In-Plane Permeability of anisotropic Fiber Reinforcements." Polymer Composites 17(1), 1996: 43-51.

George, A. Optimization of Resin Infusion Processing for Composite Materials: Simulation and Characterization Strategies. Stuttgart: University of Stuttgart, 2011.

George, A., M. Brandley, R. Dart, and C. Peterson. "Rigid Tooling for Optical 3D WEtting Permeability Measurements." Flow Processes in Composite Materials. Enschede, 2014.

Gokce, A., C. Mourad, S.G. Advani, and S.M. Walsh. "Permeability Estimation Algorithm to Simultaneously Characterize the Distribution Media and the Fabric Preform in Vacuum Assisted Resin Transfer Molding Process." Composites Science and Technology, 2005: 2129-2139.

Gonzalez, V.M. STudies of REactive Polymer Processing With Fiberglass Reinforcement. Twin Cities: University of Minnesota, 1983.

Grieser, T., and P. Mitschang. "Investigation of the Compaction Behavior of Carbon Fiber NCF for Continuous Preforming Processes." Polymer Composites, 2015.

Gutowski, T.G., T. Morigaki, and Z. Cai. "The Consolidation of Laminate Composites." Journal of Composite Material, 1987: 172-88.

Johnson, David. Strong and Light: The Evolution of the Epoxy Infusion Revolution. April 30, 2015. http://www.epoxycraft.com/strong-and-light-the-evolution-of-the-infusionrevolution/ (accessed May 25, 2017). 
Joubaud, L., V. Achim, and F. Trochu. "Numerical Simulation of Resin Infusion and Reinforcement Consolidation Under Flexible Cover." Polymer Composites 26, 2005: 417-427.

Koorevaar, A. "How Flow Analysis Technology Improves the Vacuum Infusion Process." ACMC/SAMPE Conference on Marine Composites. Plymouth, 2003.

—. "Simulation of Injection Molding Process: Delivering on the Promise." SAMPE 2002. Paris, 2002.

Korkiakoski, S., M. Haavisto, M.R. Barouei, and O. Saarela. "Experimental Compaction Characterization of Unidirectional Stitched Noncrimp Fabrics in the Vacuum Infusion Process." Polymer Composites, 2016: 2692-704.

Lawrence, J.M., K.T. Hsiao, R.C. Don, and S.G. Advani. "An Approach to Couple Mold Design and On-Line Control to Manufacture Complex Composite Parts by Resin Transfer Molding." Composites Part A: Applied Science and Manufacturing 33(7), 2002: 981-990.

Martin, B., S. Comas-Cardona, C. Binetruy, N. Billon, J.L. Bouvard, and P Lucas. "Influence of Fabrics' Design Parameters on the Morphology and 3D Permeability Tensor of QuasiUnidirectional Non-Crimp Fabrics." Composites Part A: Applied Science and Manufacturing, 2016: 470-9.

Martin, G.Q., and J.S. Son. "Fluid Mechanics of Mold FIlling for Fiber Reinforced Plastics." ASM/ESD 2nd Conference on Advanced Composites. Dearborn, 1986.

Mazumdar, S. "Growth opportunities: Materials innovation will drive composites usage to new heights." Composites World. May 1, 2012.

http://www.compositesworld.com/columns/growth-opportunities-materials-innovationwill-drive-composites-usage-to-new-heights.

Modi, D. Modelling and Active Control of the Vacuum Infusion Process for Composites Manufacture. Doctoral Dissertation, Nottingham: University of Nottingham, 2008.

Modi, D., M. Johnson, A. Long, and C. Rudd. "Analysis of Pressure Profile and Flow Progression in the Vacuum Infusion Process." Composite Science and Technology, 2009: 1458-64.

Ouagne, P., and J. Bréard. "Continuous Transverse Permeability of Fibrous Media." Composites Part A: Applied Science and Manufacturing, 2010: 22-8.

Pan, R., Z. Liang, C. Zhang, and B. Wang. "Statistical Characterization of Fiber Permeability for Composite Manufacturing." Polymer Composites 21(6), 2000: 996-1006.

Parnas, R.S., and A.J. Salem. "A Comparison of the Unidirectional and Radial In-Plane Flow of Fluids Through Woven Composite Reinforcements." Polymer Composites 14(5), 1993: 383-94. 
Parnas, R.S., J.G. Howard, T.L. Luce, and S.G. Advani. "Permeability Characterization Part I: A Proposed Standard Reference Material for Permeability." Polymer Composites 16(6), 1995: 429-45.

Parnas, R.S., K.M. Flynn, and M.E. Dal-Favero. "A Permeability Database for Composite Manufacturing." Plymer Composites 18(5), 1997: 623-633.

Patel, N., and L. James Lee. "Effects of Fiber Mat Architecture on Void Formation and Removal in Liquid Composite Molding." Polymer Composites, 1995: 386-399.

Performance Composites Inc. n.d. http://www.performancecomposites.com/about-compositestechnical-info/122-designing-with-fiberglass.html (accessed June 5, 2017).

Pillai, K.M. "Modeling the Unsaturated Flow in Liquid Composite Molding Processes: A Review and Some Thoughts." Journal of Composite Materials, 2004: 97-118.

Polyworx. Vacuum Infusion of a Contest 55. April 1999. http://www.polyworx.com/apz/cnplx/ (accessed February 1, 2015).

Robitaille, F., and R. Gauvin. "Compaction of Textile Reinforcements for Composites Manufacturing. III: Reorganization of the Fiber Network." Polymer Composites, 1999: 48-61.

Saunders, R.A., C. Lekakou, and M.G. Bader. "Compression in the Processing of Polymer Composites 2. Modelling of the Viscoelastic Compression of Resin-Impregnated Fibre Network." Composites Science and Technology, 1999: 1483-94.

Scholz, S., J.W. Gillespie, and D. Heider. "Measurement of Transvers Permeability Using Gaseous and Liquid Flow." Composites Part A: Applied Science and Manufacturing, 2007: 2034-40.

Song, X. Vacuum Assisted Resin Transfer Molding (VARTM): Model Development and Verification. Doctoral Dissertation, Virginia Polytechnic Institute, 2003.

Stadtfeld, H.C., M. Erninger, S. Bickerton, and S.G. Advani. "An Experimental Method to Continuously Measure Permeability of Fiber Preforms as a Function of Fiber Volume Fraction." Journal of Reinforced Plastics and Composites, 2002: 879-99.

Stedile. Felt Permeability Testing Apparatus. US Patent 3577767. 1971.

Terzaghi, K., R.B. Peck, and G. Mesri. Soil Mechanics in Engineering Practice. New York: John Wilery \& Sons, Inc., 1996.

Trochu, F, E Ruiz, V Achim, and S Soukane. "Advanced Numerical Simulation of Liquid Composite Molding for Process Analysis and Optimization." Composites Part A: Applied Science and Manufacturing, 2006: 890-902. 
Vernet, N., E. Ruiz, S. Advani, et al. "Experimental Determination of the Permeability of Engineering Textiles: Benchmark II." Composites Part A: Applied Science and Manufacturing, 2014.

Williams, C., J. Summerscales, and S. Grove. "Resin Infusion Under Flexible Tooling (RIFT)." Composites Part A: Applied Science and Manufacturing, 1996: 517-24.

Williams, J.G., C.E.M. Morris, and B.C. Ennis. "Liquid Flow Through Aligned Fiber Beds." Polymer Engineering and Science 14, 1974: 413-419.

Wu, C.H., T. James Wang, and L. James Lee. "Trans-Plane Fluid Permeability Measurement and Its Applications in Liquid Composite Molding." Polymer Composites, 1994: 289-98. 


\section{APPENDIX A. TOOL DESIGNS}

The tool drawings supplied below are to supplement the descriptions found in Chapter 3:

Methodology. They have been modeled in SolidWorks CAD software and are meant to aid anyone wishing to replicate the study presented in this thesis. 


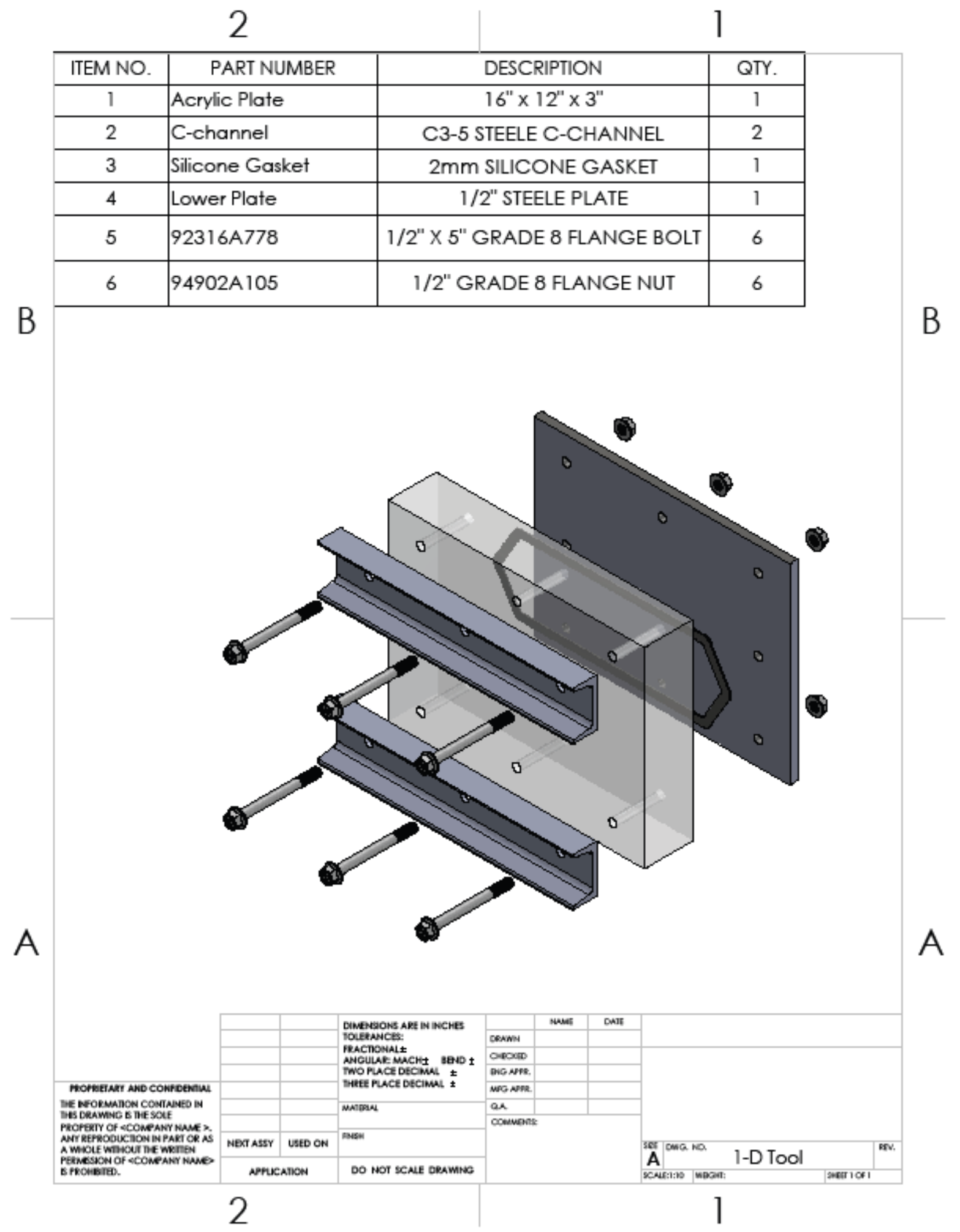

1-D Tool Assembly 


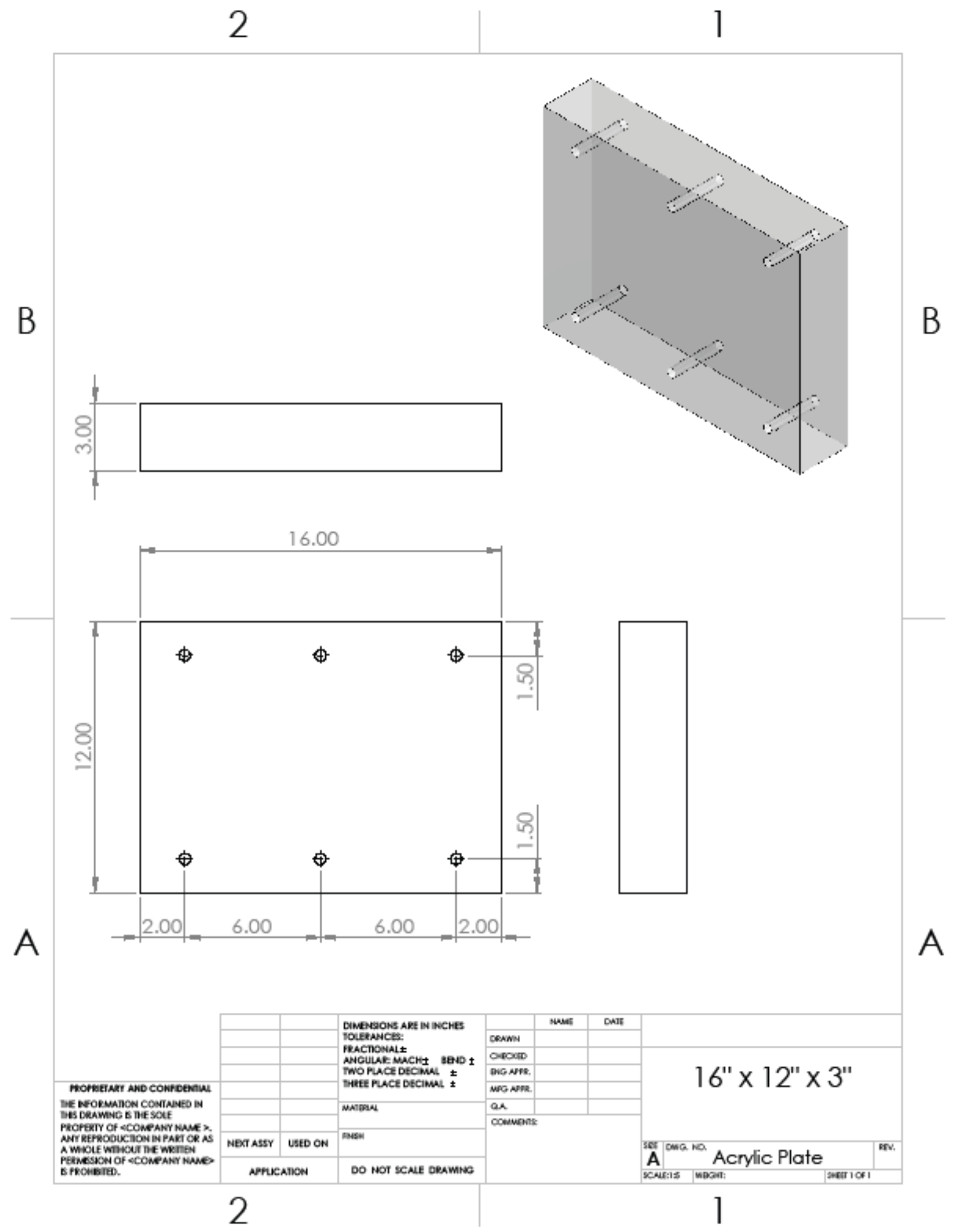

1-D Tool Acrylic Sheet 


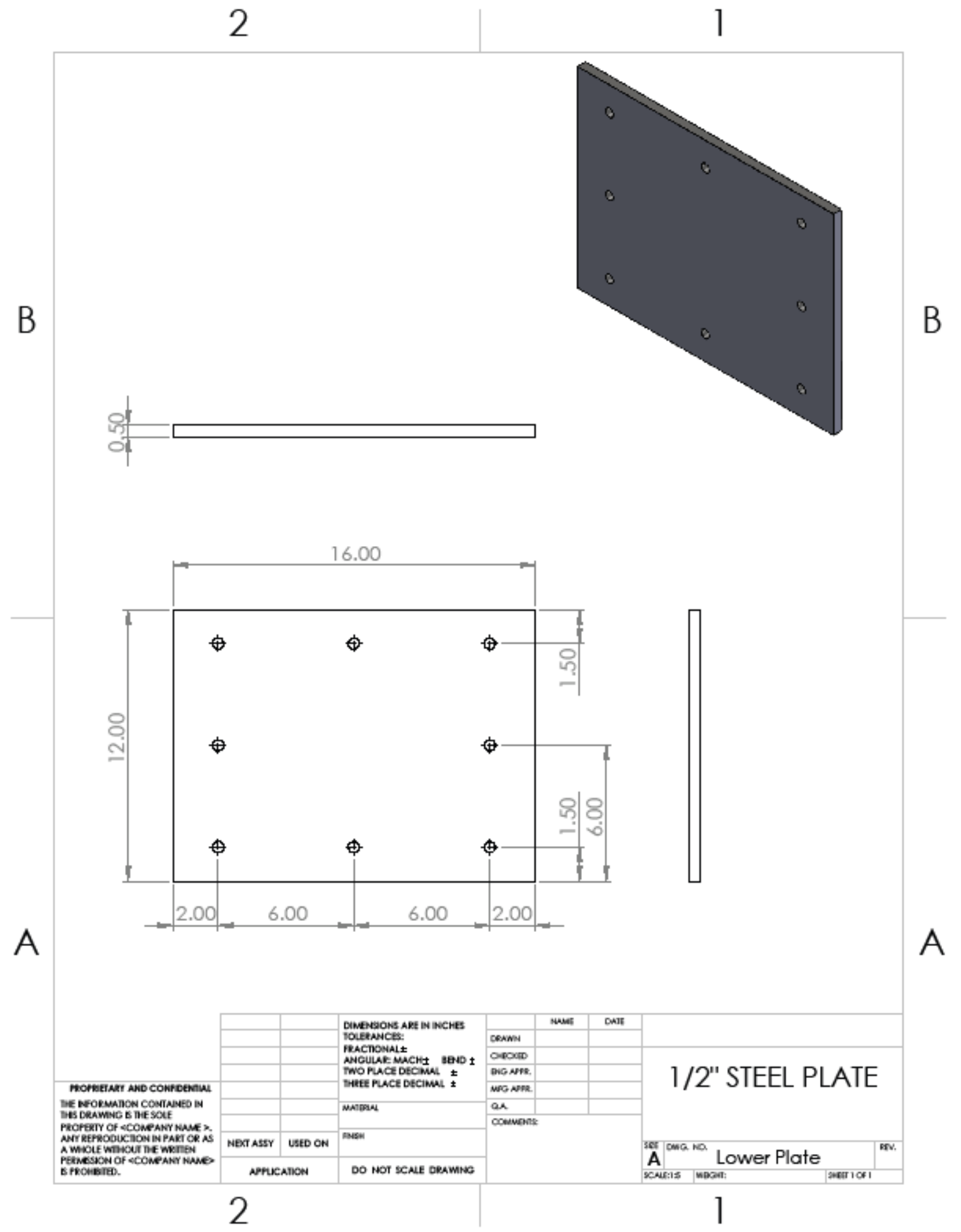

1-D Tool Lower Plate 


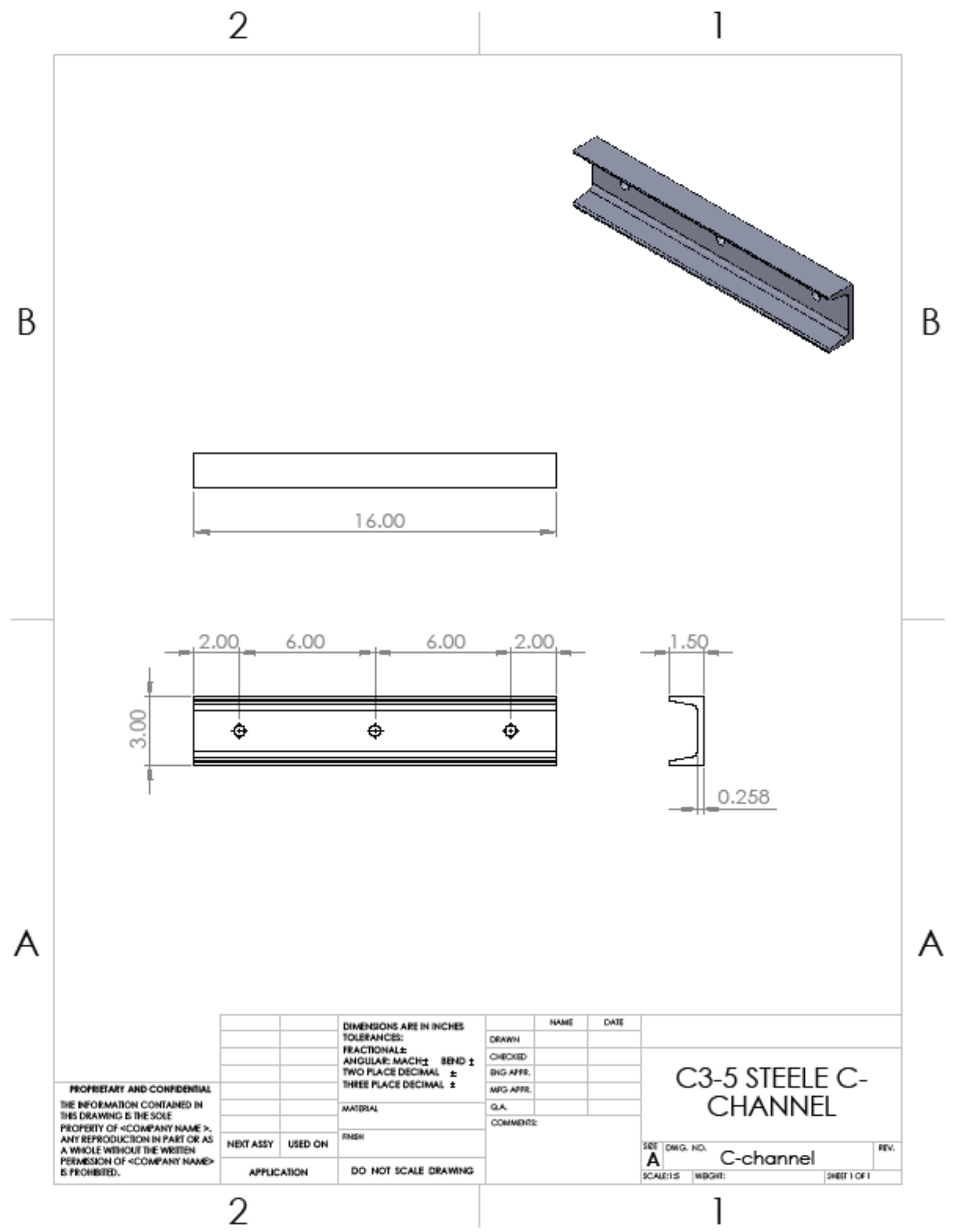

\section{1-D Tool C-Channel}




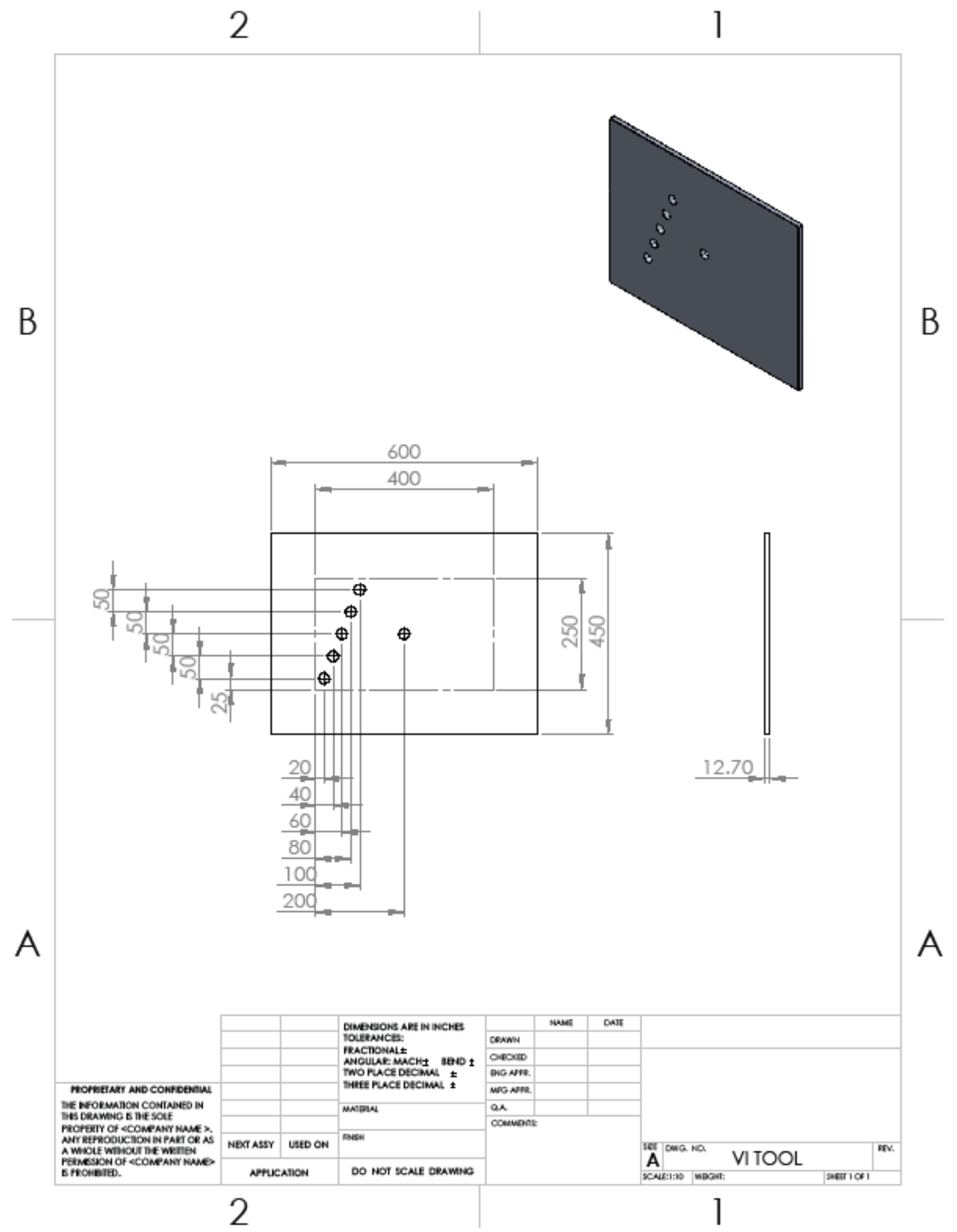

Vacuum Infusion Tool Plate 


\section{APPENDIX B. ANALYTICAL MODEL CODE}

The code presented below is a script implemented in Matlab to solve the analytical flow model of Equation 2-5. The compressibility is modeled by Equation 3-8 and the permeability by Equation 2-2 (the Kozeny-Carman equation). This script is setup to optimize the fitting parameter in Equation 2-2, the Kozeny constant, $k$, which results in the best fit of length vs time data with the experimental results.

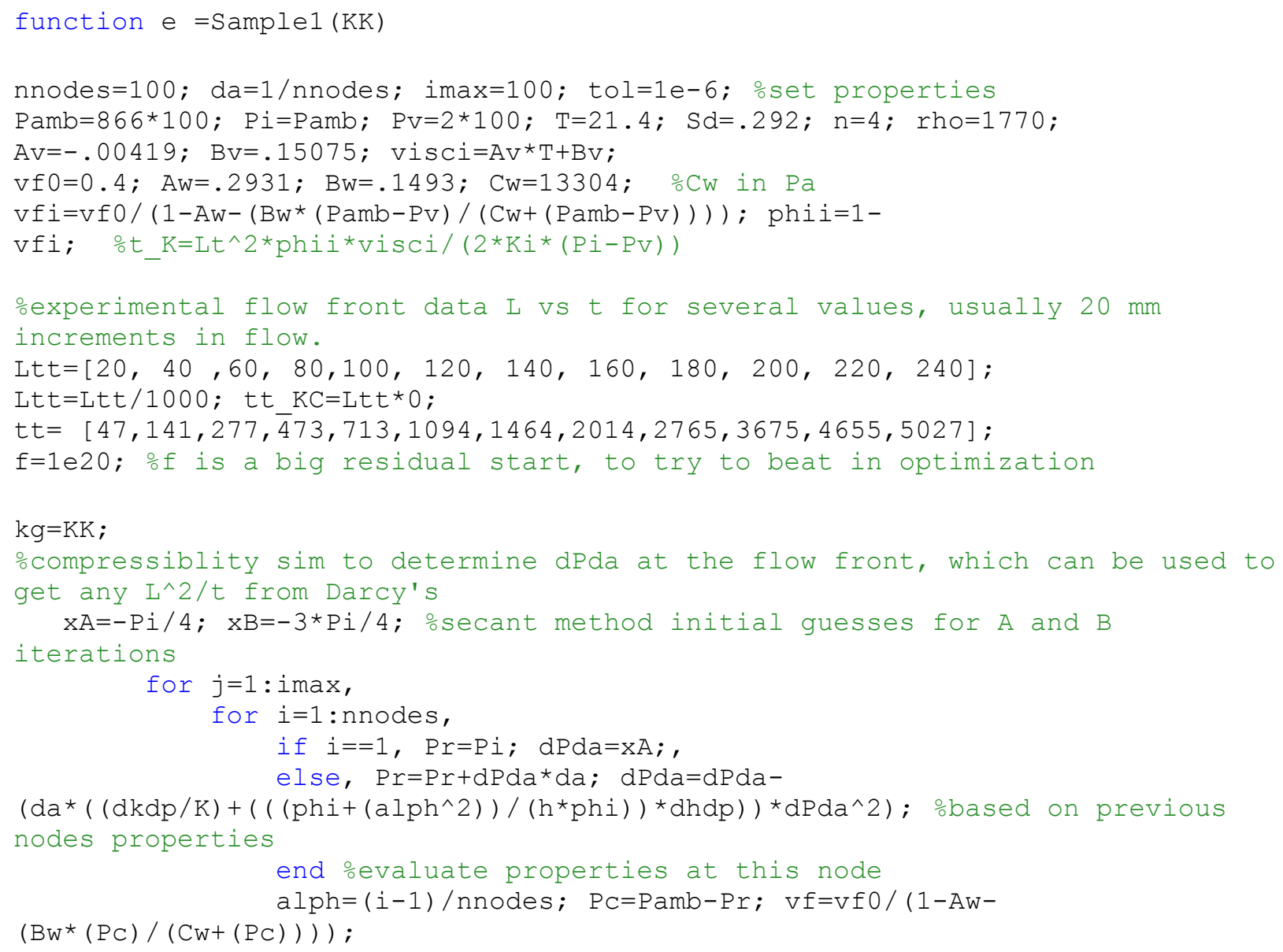




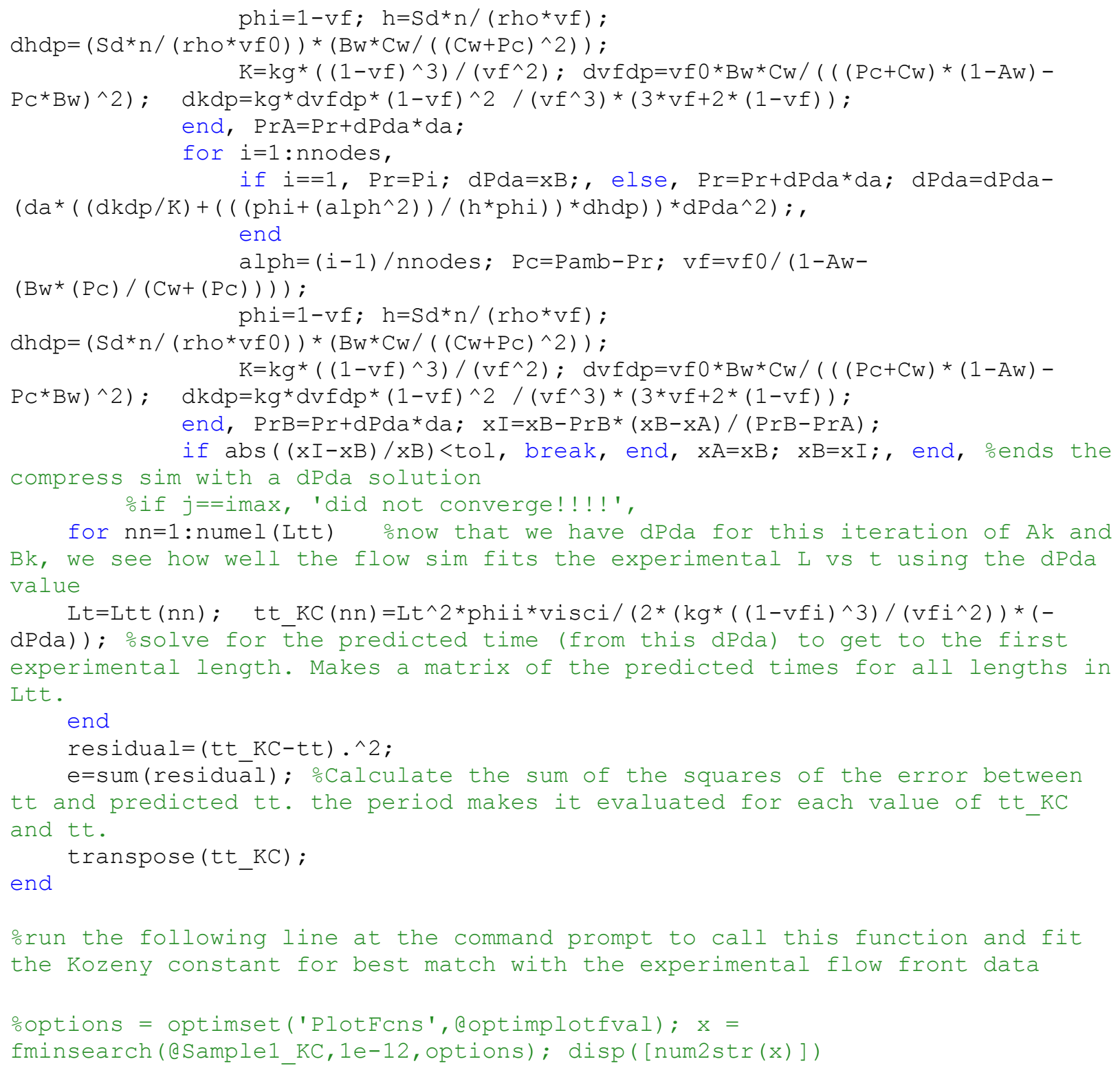

